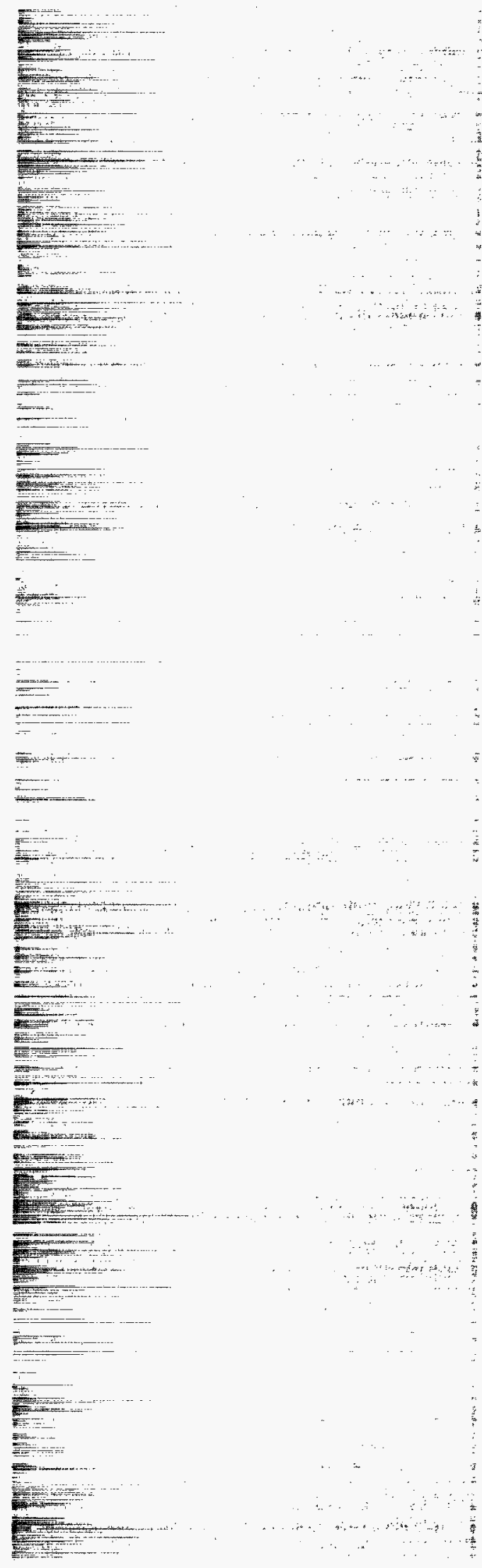$$
31
$$ \\ Implementation Plan for the \\ Operations Center Upgrade Project
}

\section{Los Alamos \\ NATIONAL LABORATORY}

Los Alamos National Laboratory is operated by the University of California for the United States Department of Energy under contract W-7405-ENG-36. 
Edited by Hector Hinojosa, Group CIC-1

Photocomposition by Joyce A. Martinez, Group CIC-1

An Affirmative Action/Equal Opportunity Employer

This report zoas prepared as an account of work sponsored by an agency of the United States Government. Neither The Regents of the University of California, the United States Government nor any agency thereof, nor any of their employees, makes any warranty, express or implied, or assumes any legal liability or responsibility for the accuracy, completeness, or usefulness of any information, apparatus, product, or process disclosed, or represents that its use would not infringe privately owned rights. Reference herein to any specific commercial product, process, or service by trade name, trademark, manufacturer, or othenvise, does not necessarily constitute or imply its endorsement, recommendation, or favoring by The Regents of the University of California, the United States Government, or any agency thereof. The views and opinions of authors expressed herein do not necessarily state or reflect those of The Regents of the University of Califormia, the United States Government, or any agency thereof. The Los Alamos National Laboratory strongly supports academic freedom and a researcher's right to publish; therefore, the Laboratory as an institution does not endorse the viewopoint of a publication or guarantee its technical correctness. 


\section{DISCLAIMER}

Portions of this document may be illegible in electronic image products. Images are produced from the best available original document. 
Implementation Plan for the

Operations Center Upgrade Project
N. G. Pope
R. E. Brown
W. J. Turner
K. Courtney
E. L. Joseph
D. Jones
S. Pruett 


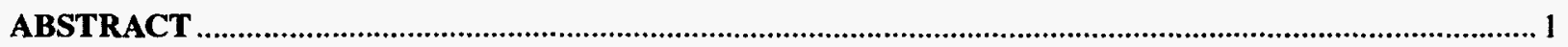

I. INTRODUCTION

I. PROBLEM STATEMENT AND PURPOSE OF DOCUMENT ….................................................. 1

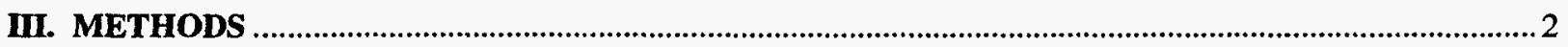

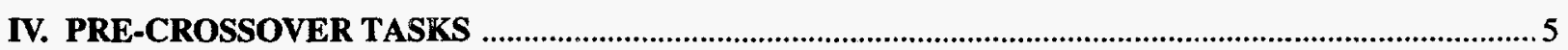

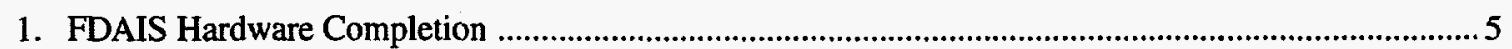

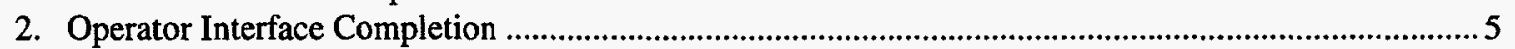

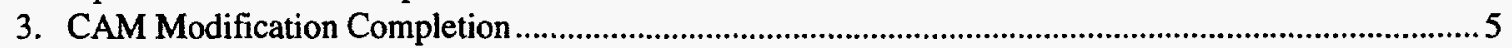

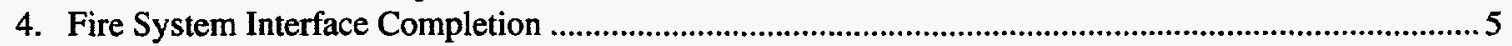

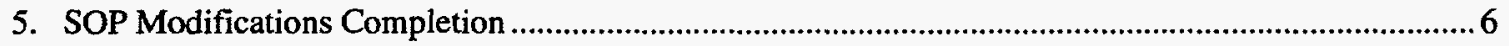

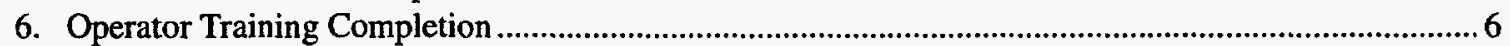

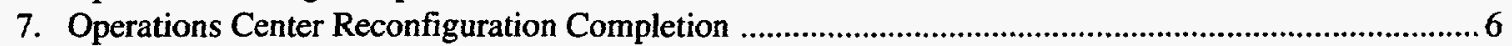

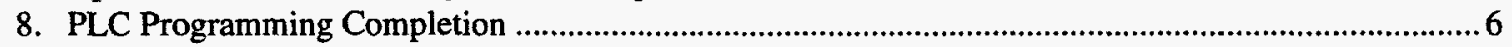

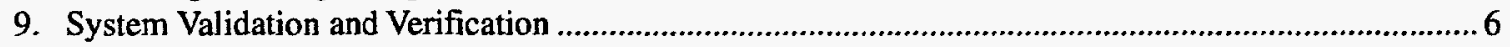

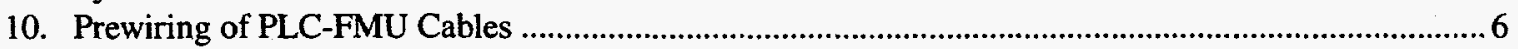

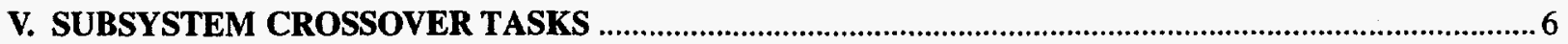

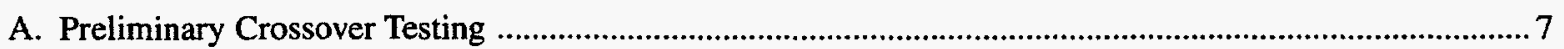

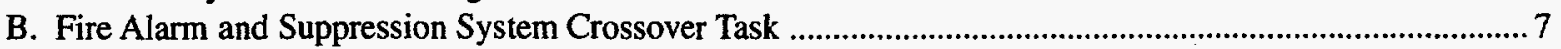

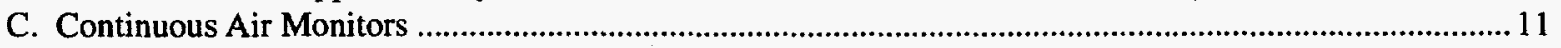

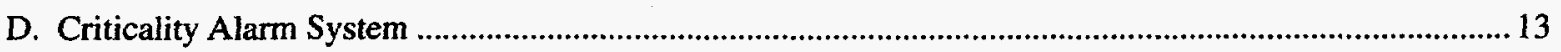

E. Electrical Switchgear System ............................................................................................................... 15

F. Heating, Ventilation, and Air Conditioning (HVAC) ........................................................................... 15

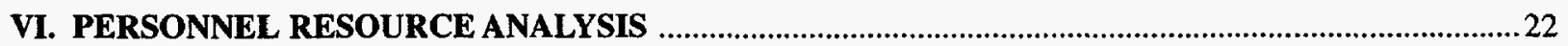

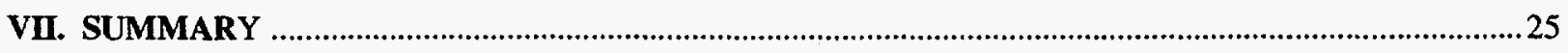

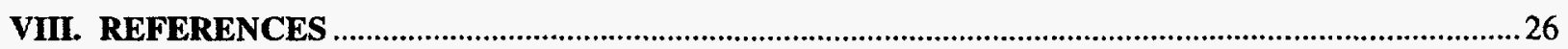

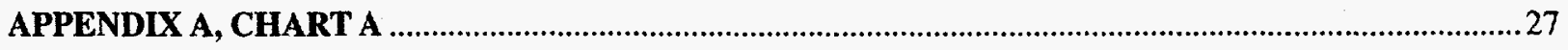

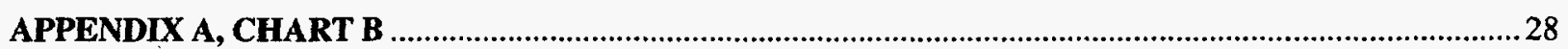

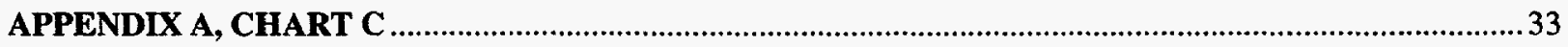

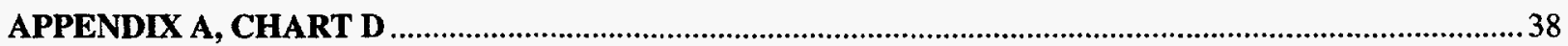




\title{
IMPLEMENTATION PLAN \\ FOR THE \\ OPERATIONS CENTER UPGRADE PROJECT
}

\author{
by \\ N. G. Pope, R. E. Brown, W. J. Turner, \\ K. Courtney, E. L. Joseph, D. Jones, and S. Pruett
}

\begin{abstract}
The crossover from the existing TA-55 Facility Control System to a newly constructed system will be implemented over a four-month period beginning the first week in January, 1997. Personnel requirements and task durations have been established using planning and scheduling project management techniques. Each facility subsystem will be crossed over on individual four-day maintenance weekends during which building PF-4 will be exclusively reserved for these tasks. Each subsystem will be validated prior to the resumption of normal programmatic activities. PF-4 will be open for normal activities between each four-day maintenance weekend. Crossover will not begin until specifically outlined tasks are completed.
\end{abstract}

\section{INTRODUCTION}

The objective of the Operation Center Upgrade project is to replace the existing Technical Area (TA) 55 Facility Control System (FCS) while maintaining facility safety standards and minimizing programmatic downtime. The project has been developed into two distinct parts-the Facility Data Acquisition Interface System (FDAIS), which replaces existing field multiplex units (FMUs) with a network of programmable logic controllers (PLCs), and the Systems Integration project, which integrates existing facility instrumentation with the FDAIS and new computers. Each has had requirements outlined in detail. ${ }^{1-8}$ This document sets forth the method for integrating the two parts, in essence, integrating the FDAIS with the facilities network of sensors and controllers, as well as with the Operations Center computer system. The purpose of this document is to outline the integration activities in great enough detail such that the integration effort can proceed and normal facility operations affected by these activities can make appropriate adjustments to work schedules. In addition, this document will be used to assist in the actual planning and execution of the integration by serving as the primary mechanism to review planned procedures.

This document does not define individual instrumentation or wiring points to be crossed over. These are documented separately in individual work permits or procedures.

\section{PROBLEM STATEMENT AND PURPOSE OF DOCUMENT}

The FCS currently monitors key facility systems in order to ensure that these systems remain within the allowable facility safety envelope. The simplest method of transition (referred to as the "crossover" period) from the old system to the new system would be to stop all programmatic operations within PF-4 
and prevent all workers from returning to their duties for as long as it takes for completion. However, because of the pressing and unique nature of the work performed at TA-55, this option is not available.

The crossover period has been compared to trying to replace an engine in an automobile as it is driving down the freeway. In either case, the actual crossover requires that the system stop for some amount of time. The preference, of course, is to schedule the downtime to occur at known times for known durations. The implementation plan outlined here does exactly that. A second preference is to have all work that can be performed off-line from the currently operating system be done so whenever possible. Again, this document outlines these steps.

The purpose of this document is to (1) establish the approach and methods to complete the crossover from old to new systems, (2) estimate personnel requirements in order to accurately schedule resources, (3) provide a written document to facilitate review and approval from the Nuclear Materials Technology (NMT) Division Director and the TA-55 Facility Manager to proceed with implementation, and (4) notify groups conducting work at TA-55 as to the nature and duration of planned PF-4 outages so that alternative activities can be scheduled during these times. This document does not prohibit changes in tasks, the orders in which tasks are performed, the composition of work crews, the durations of tasks, or any other changes required by the project to accomplish the outlined goals.

\section{METHODS}

Organization of Tasks. System implementation tasks have been organized into the following three categories:

Pre-Crossover Tasks. These tasks must be complete before the beginning of system crossover in order to ensure minimal downtime.

Subsystem Crossover Tasks. System crossover will occur on a system-by-system basis. All PF-4 downtime occurs during these tasks.

Validation and Verification (V\&V) Tasks. These tasks provide the technical and administrative checks to assure that the crossover tasks have been successfully performed and that the new system is ready for use. Subsystem capability is verified using the official Operational Surveillance Requirements (OSRs) wherever possible to validate proper subsystem operation prior to the release of PF- 4 to general work. V\&V and other testing plans are outlined in detail in a separate report. ${ }^{9}$

Figure 1 illustrates the relationship between these tasks and associated subtasks.

Scheduling. The crossover schedule is defined in Figure 2. All crossover tasks are scheduled to start on January 3,1997. This date was originally set based on a master project schedule established in August 1994. During the original planning of the project, a schedule was set based on somewhat scarce information regarding required tasks, methods, and funding levels. This master schedule continues to provide project milestone clates that are reasonable and accurate. It is possible, however, that the start of system implementation can be moved forward by as much as 4 months, in which case the project schedule will be updated as required. As the preimplementation tasks are completed, the implementation starting date becomes easier to estimate until a definite date is selected. The circumstances under which the implementation can proceed earlier than scheduled are outlined in the section of this report that discusses the Pre-Crossover Tasks. In the event that these tasks are completed ahead of schedule, the start date of the Crossover Tasks may be moved up as well. In this event, groups with operations in PF-4 will be notified and the start of Crossover will commence according to their schedules.

Resource Loading. Resource estimates are not generally based on prior experience as this installation is a unique one-time event. Resource estimates have been based on predictions of task durations and forecasts of required resources for the tasks. A preliminary testing period has been scheduled to validate the accuracy of the task sequence, resource requirements, and task duration.

Downtime. System crossover relies on two categories of downtime: (1) Maintenance Weekends and (2) Plant Stand-down. A new work schedule has been implemented at TA-55 which uses 10-hour work days to provide a 4-day weekend every other week during which the only allowable work in building Plutonium Facility 4 (PF-4) is related to maintenance. All subsystem crossover tasks, except the heating, ventilation and air conditioning system (HVAC), require work to be performed during the 4-day "maintenance" weekends. It is estimated that 5 of these weekends will be required (over a period of approximately 3 months). The HVAC crossover must be performed during the two-week planned plant stand-down. 


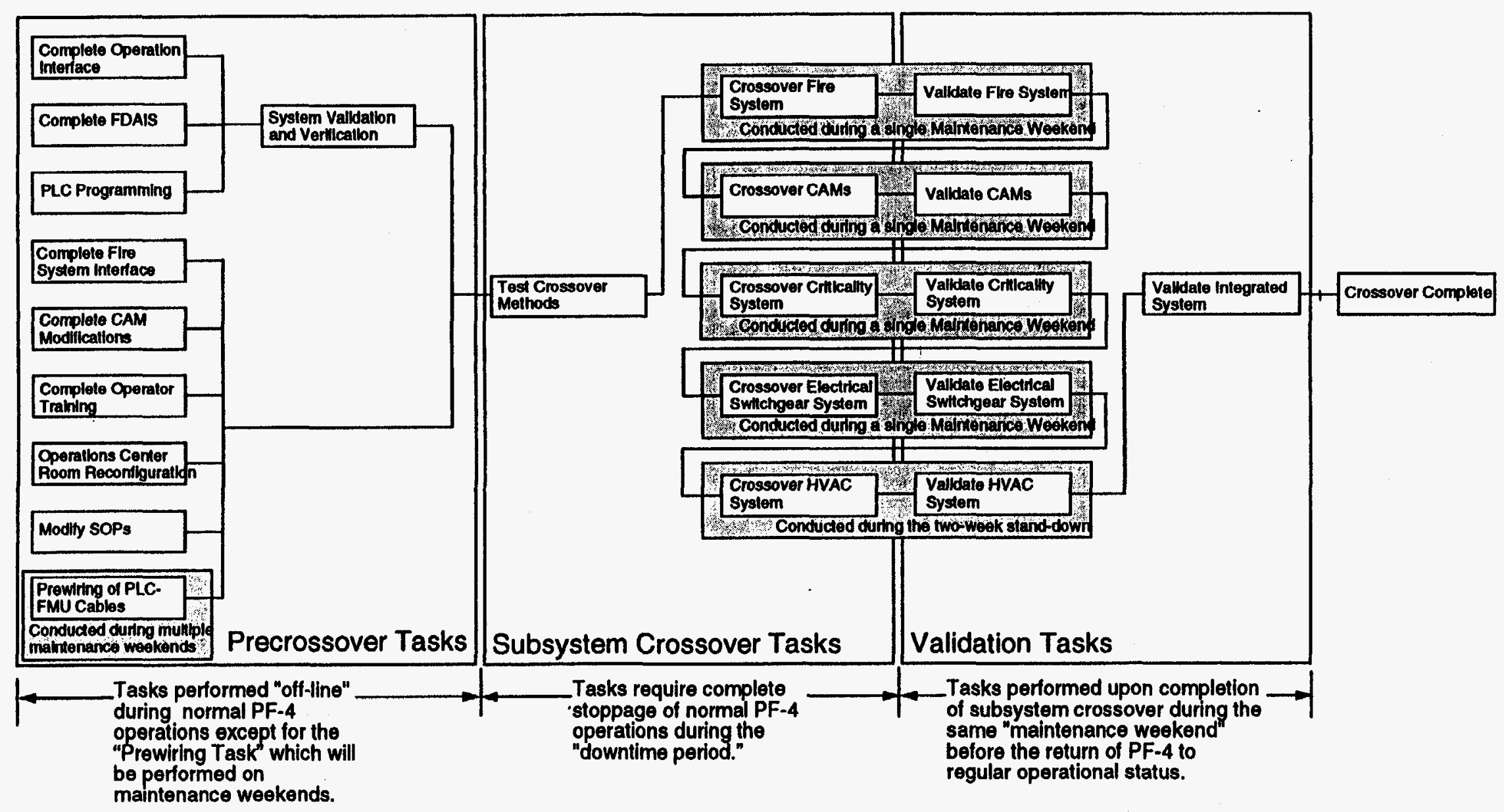

Figure 1. Graphical depiction of the three required categories of tasks required to complete the crossover. 


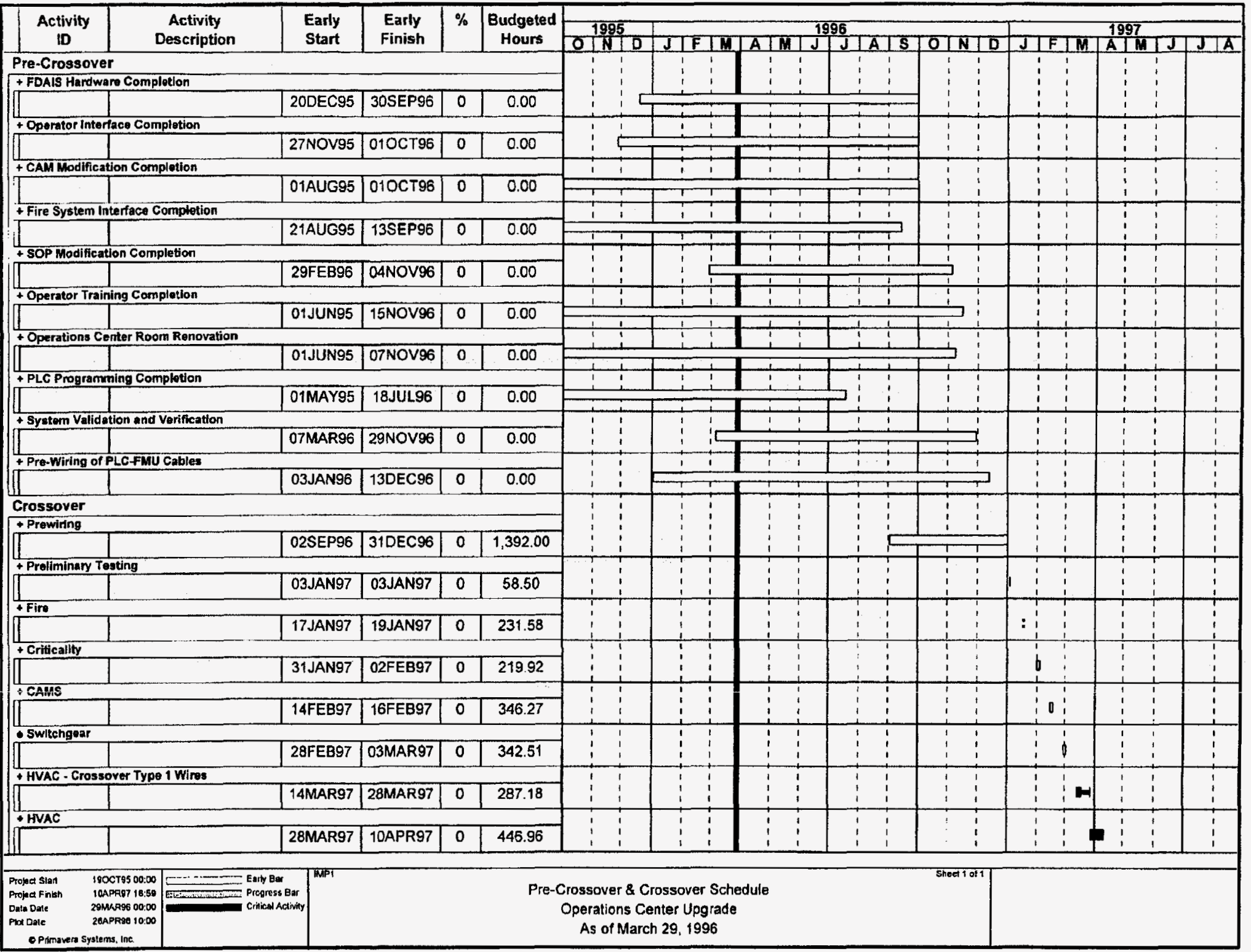

Figure 2. Overall crossover schedule showing the required Pre-Crossover and Crossover Tasks. 


\section{PRE-CROSSOVER TASKS}

Completion of the Pre-Crossover Tasks ensures that all possible work that can be done without downtime has been accomplished prior to crossover. These tasks must be completed prior to the beginning of the Crossover Tasks. The tasks have been categorized as follows:

1. FDAIS Hardware Completion.

2. Operator Interface Completion.

3. Continuous Air Monitor (CAM) Modification Completion.

4. Fire System Interface Completion.

5. Standard Operating Procedures (SOPs) Modifications Completion.

6. Operator Training Completion.

7. Operations Center Reconfiguration Completion.

8. PLC Programming Completion.

9. System Validation and Verification.

10. Prewiring of PLC-FMU Cables.

These tasks and their completion criteria (to ensure that tasks are satisfactorily completed) are defined as follows:

\section{FDAIS Hardware Completion}

Task Description. A new data acquisition system is under development which is designed to interface to individual plant sensors and single-loop controllers.

Completion Criteria. The completion of the FDAIS will be determined by the Facility Safeguards and Security (FSS)-6 Project Leader according to criteria established in the Title II document. ${ }^{3}$ This includes the installation and testing of all FCC electronics cabinets, communications (including fiber optics), electrical power wiring, and testing of lowlevel ladder-logic programming.

\section{Operator Interface Completion}

Task Description. The operator interface describes the new computer system which runs manmachine interface (MMI) software which allows personnel in the Operations Center to monitor, and in some cases, control facility subsystems. Both the computers and the MMI software will be programmed and installed in the Operations Center according to design documentation. ${ }^{5,7}$ MMI programming includes operator graphics, alarms, and data storage procedures. Programming will be performed as part of a contract with WunderlichMalec Engineering (Contract \# 0200015-3Z) which includes testing and verifications processes.

Completion Criteria. The completion of the operator interface is dependent on the successful completion of specific testing and simulations requirements. ${ }^{9}$

\section{CAM Modification Completion}

Task Description. All CAMs in use at TA-55 must be modified by Environmental Safety and Health (ESH) -4 to provide new analog and digital signals rather then the pulsed signals currently in use. This modification greatly simplifies the design of the FDAIS hardware, increases the reliability of the FDAIS system, ${ }^{4}$ and reduces equipment costs. CAM modifications are planned to occur for each CAM during the normal annual ESH-4 calibration. There are 187 CAMs interfaced to the current FCS out of an available spare inventory of 278 CAMs. Each of the installed CAMs must be modified prior to the crossover. ESH-4 is responsible for ensuring that each of these modified CAMs is operable according to their own internal quality assurance requirements.

Completion Criteria. Successful completion of work in this category will be determined when ESH4 has notified NMT- 8 and ESH- 1 by memorandum that all of the CAMs installed at TA-55 have been modified according to the new interface designs.

\section{Fire System Interface Completion}

Task Description. A project is in progress to upgrade the hardware which sends fire alarm signals to the FCS. A new alarm relay system will be installed in conjunction with the TA-55 central alarm processor so that the majority of fire-related signals can be picked up at one central location rather than at multiple FMU locations. This project is being conducted jointly by NMT-8, FSS-21, and Johnson Controls, Inc. (JCI). The remaining fire points interface directly to the FCS at FMU termination panels. The crossover of these points is discussed in later sections.

Completion Criteria. The new fire system interface will be complete when the new relay panel has been installed and tested according to a work order with the JCI fire maintenance crew. In addi- 
tion, the interface to FCC-1B has been completed and all fire interface points verified as operable according to a memorandum issued by FSS- 21 .

\section{SOP Modifications Completion}

Task Description. Several NMT-8 procedures for the Operations Center must be modified to include the use of new computer equipment. This work will be completed by the Operations Center Supervisor.

Completion Criteria. The completion of SOP modifications will be determined when a memorandum has been issued to the NMT-8 Group Office from the Operations Center Supervisor confirming that all required SOP modifications are complete.

\section{Operator Training Completion}

Task Description. Operations Center personnel will require new training to be certified in the use of new computer equipment. Training will be conducted primarily by commercial vendors. A training schedule and roster is under development.

Completion Criteria. The completion of training requirements will be determined when a memorandum has been issued to the NMT-8 Group Office from the Operations Center Supervisor confirming that all training requirements are complete.

\section{Operations Center Reconfiguration Completion}

Task Description. The Operations Center will require extensive layout reconfiguration in order to simultaneously operate both the old FCS equipment as well as the new equipment. The scope of these room modifications has been developed. ${ }^{8}$ This work will be conducted jointly by NMT- 8 and JCI.

Completion Criteria. The completion of the reconfiguration of the Operations Center will be determined when new computers have been proved operational as per a memorandum from the Operations Center Upgrade Project Leader to the NMT-8 Group Office.

\section{PLC Programming Completion}

Task Description. All PLCs installed as part of the FDAIS will be programmed according to system design specifications. ${ }^{7}$ Programming will be performed as part of a contract with Wunderlich-Malec Engineering (Contract \# 0200015-3Z) and will include testing and verifications processes.

Completion Criteria. The PLC programming will be complete when all validation and verification activities have been successfully completed. ${ }^{9}$

\section{System Validation and Verification}

Task Description. All new equipment must pass certain formalized tests in order to be allowed to operate with the new system. These tests range from simple inspections and checks to exhaustive simulations. The purpose of the tests is to verify that all components are functioning as intended in an integrated configuration. As many of the tests as possible have been scheduled as part of the PreCrossover Tasks in order to minimize time requirements during PF-4 shutdown. A formal test plan is under development. ${ }^{11}$

Completion Criteria. The System Validation and Verification process will be considered completed when an appropriate memorandum is issued from the Operations Center Supervisor to the NMT-8 Group Office.

\section{Prewiring of PLC-FMU Cables}

Task Description. Wiring harnesses will be installed in each PLC cabinet as part of the FDAIS project. These harnesses will be pulled through conduit into the existing FMU termination panels (TPs) during this prewiring task. In some cases, additional prewiring will occur in order to facilitate wiring procedures as part of the subsystem crossover tasks. This will consist of measuring and cutting individual signal wires to proper length, attaching termination lugs, routing signal wires within the TPs, and securing wires using wire ties. These tasks will be conducted on maintenance days.

Completion Criteria. The completion of this task will be designated by the Operations Center Supervisor by a memorandum to the NMT-8 Group Office upon completion of all prewiring for each TP.

\section{SUBSYSTEM CROSSOVER TASKS}

Subsystem crossover tasks have been scheduled to occur during "maintenance" days or during a twoweek stand-down period at which time PF-4 is specifically reserved for facilities work (Fig. 3). No other work will be allowed in PF-4 during this 
period. All crossover work will be coordinated by NMT-8 Area Work Supervisors in conjunction with the Operations Center.

Several subsystems interface to an audible alarm generator located in the Operations Center. All audible alarms are triggered by a $24-\mathrm{V}$ discrete signal from the FMU located in the Operations Center. All of these signals will be crossed over to the new PLC in the Operations Center on a subsystem basis.

Each subsystem crossover task is described according to the following categories:

1. Description of Approach and Work Flow Analysis. The work is described in moderate detail.

2. Schedule. Based on analyses of work tasks and available personnel, schedules were developed which include start and finish dates and task durations.

3. Identification of Required Personnel. The composition of work crews is defined according to required skills.

4. Verification Overview. Procedures are under development to identify required tests, analysis, and simulation in order to ensure that system functionality is fully met. The approach to these verification procedures is described in moderate detail. A separate document describing the exact test and acceptance procedure is under development. ${ }^{11}$

\section{A. Preliminary Crossover Testing}

\section{Description of Approach and Work Flow}

Analysis. In order to verify assumptions used to calculate work schedules during crossover, to confirm specific aspects of the crossover tasks to be performed, and to validate verification procedures, a test of each subsystem crossover method will be conducted prior to full-scale crossover. Based on the results of these tests, subsequent crossover schedules and task descriptions may require adjustment. While this may affect the ultimate crossover completion schedule, such testing of methods and required work duration is prudent prior to the beginning of the actual crossover of each individual system.

2. Schedule. This task has been scheduled to occur prior to the actual crossover of any subsystem and each of the 5 subsystems will undergo this preliminary testing during a single 4-day maintenance weekend. Each individual subsystem crossover task will be tested on successive days according to the schedule outlined in Figure 4.

\section{Identification of Required Personnel. Work Crew:}

2 Electronic Technicians (NMT-8)

2 Radiological Control Technicians (ESH-1)

1 Radiological Instrumentation Technician (ESH-4)

Number of Crews: 1

Shared Crew:

1 HVAC Engineer (NMT-8)

1 Operations Center System Administrator (NMT-8)

1 Wunderlich-Malec System Engineer

1 Electrical Engineer (NMT-8)

4. Verification Overview. Verification procedures developed for each individual subsystem crossover will also be tested during this task.

\section{B. Fire Alarm and Suppression System Crossover Task}

\section{Description of Approach and Work Flow} Analysis. Figure 5 outlines the procedural steps involved with the crossover of the fire system. Unlike the other FCS subsystems, the fire system will be partially connected to the existing FCS in parallel to the new system. The existing FCS connects to the fire system at FMU points located throughout the site. The new system connects to most of the fire points directly at the "BRASS" fire alarm panel located outside of the Operations Center in PF-3. Prior to the start of crossover, the BRASS panel will be reconfigured with a special set of relays which are actuated during fire events. These relays will be wired directly into a PLC remote Input/Output (I/O) rack which is reserved uniquely for that purpose. About 200 other points related to the fire system must be picked up by field PLCs located in PF-4 as well. Consequently, the fire system crossover consists of both the connections to the BRASS panel as well as the crossover of field FMU points.

The fire relays can be monitored by the new FCS without affecting the operability of the current FCS system, which allows the new FCS performance to be observed prior to crossover. During Crossover, the field points will be crossed over to the PLCs and the fire alarm outputs will be tied into the audible alarm system.

FMUs and associated 24-VDC power supplies will remain operational ("hot") during crossover.

2. Schedule. Figure 6 outlines the order in which FMUs will be worked on. The order was determined by analyzing the number of fire system points in each TP and the available work time during a 10-hour shift. Figure 3 shows the schedule for the fire system crossover with respect to the overall crossover schedule. 


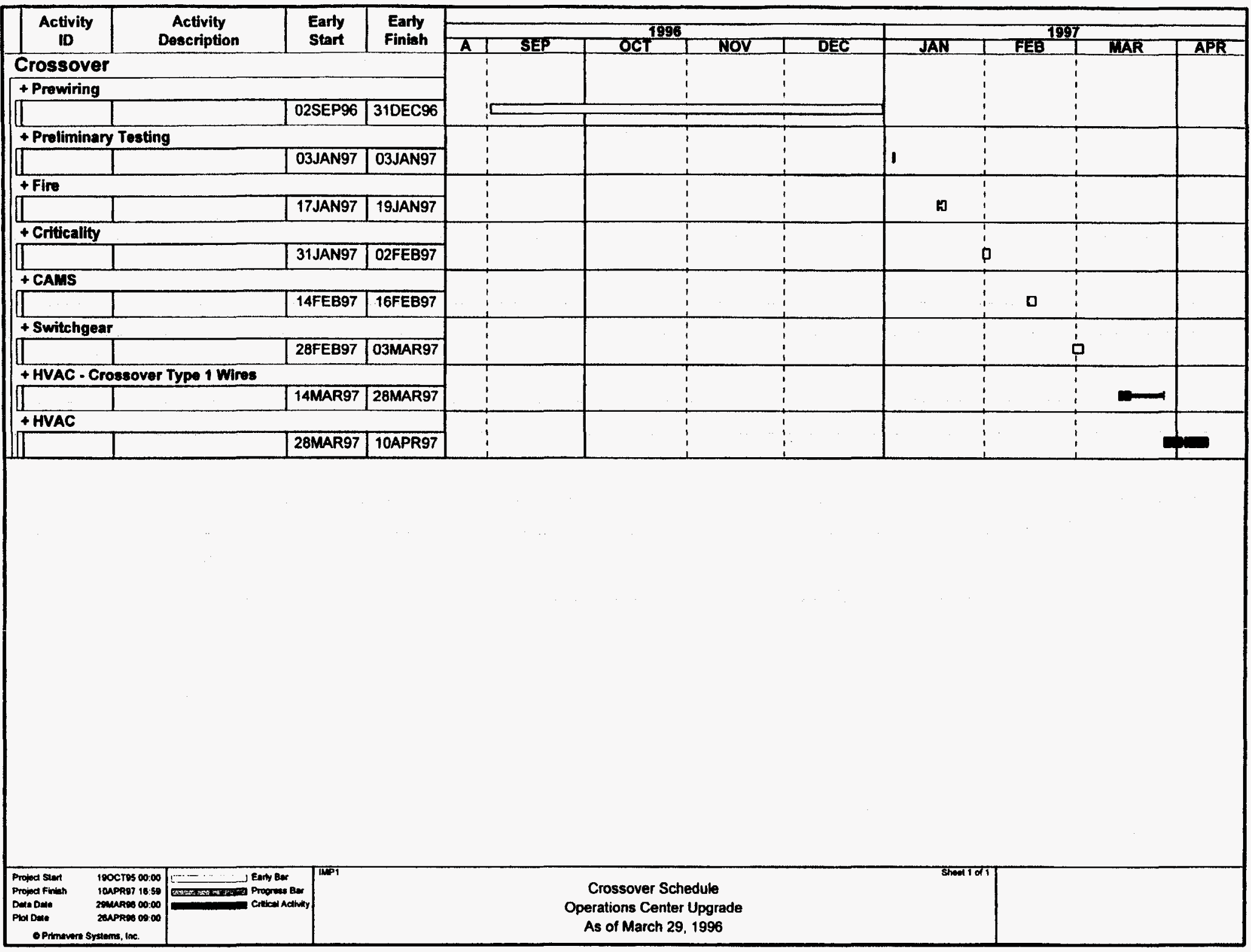




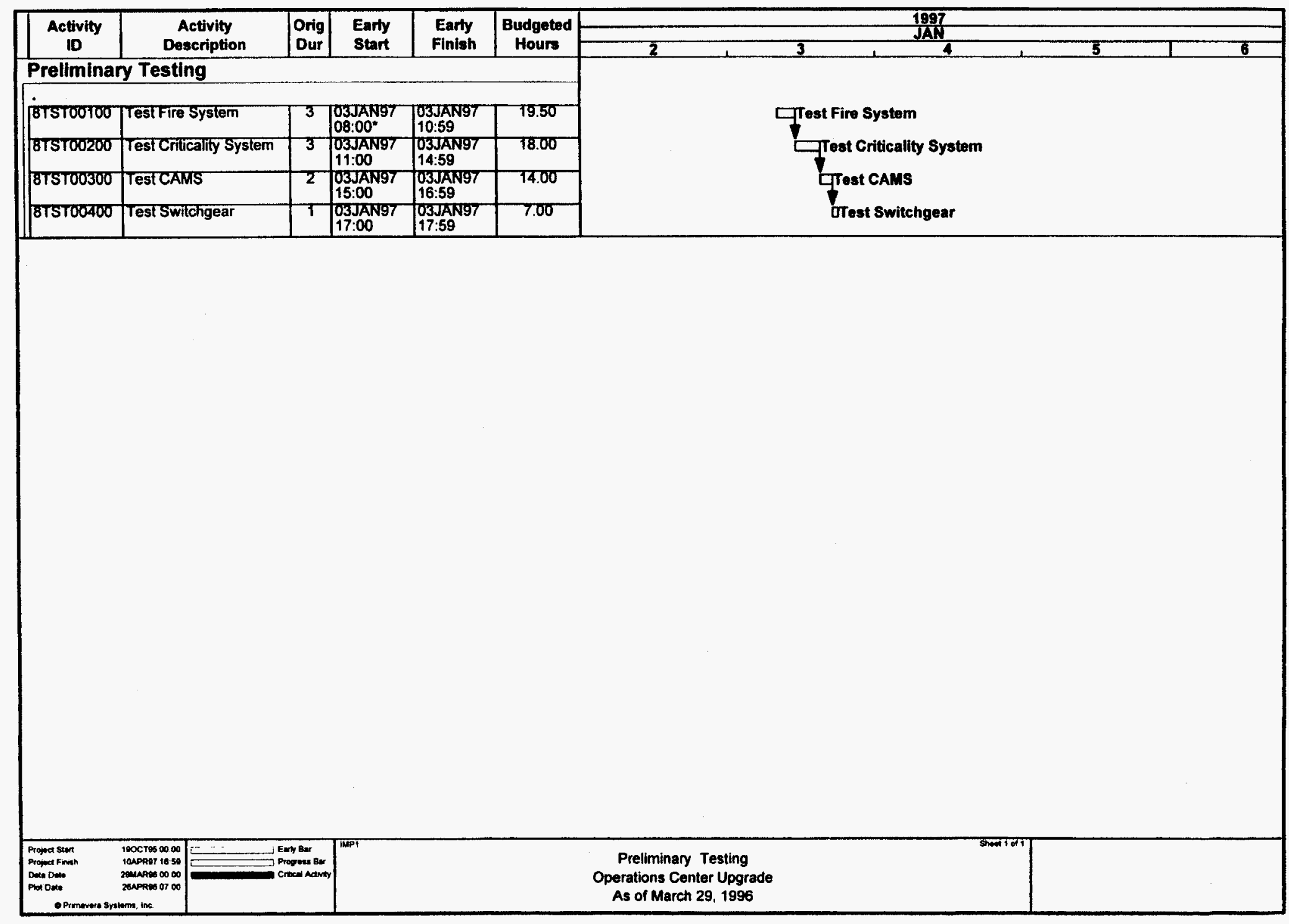

Figure 4. Outline of the order in which individual subsystem crossover methods will be tested. 


\section{FIRE}

Field 110

$y$

\begin{tabular}{|l|}
\hline Write Special Work Pormit \\
\hline TSM OHRS \\
\hline
\end{tabular}

Develop Wiring Check List \& Schedule

TSW ITEC

104hs

Remove Wires to Alarms from TP

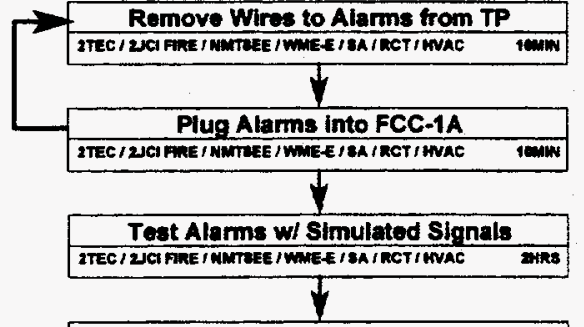

Crossover

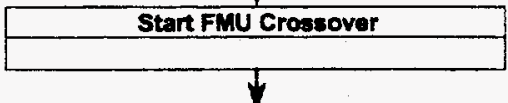

$\sqrt{1}$

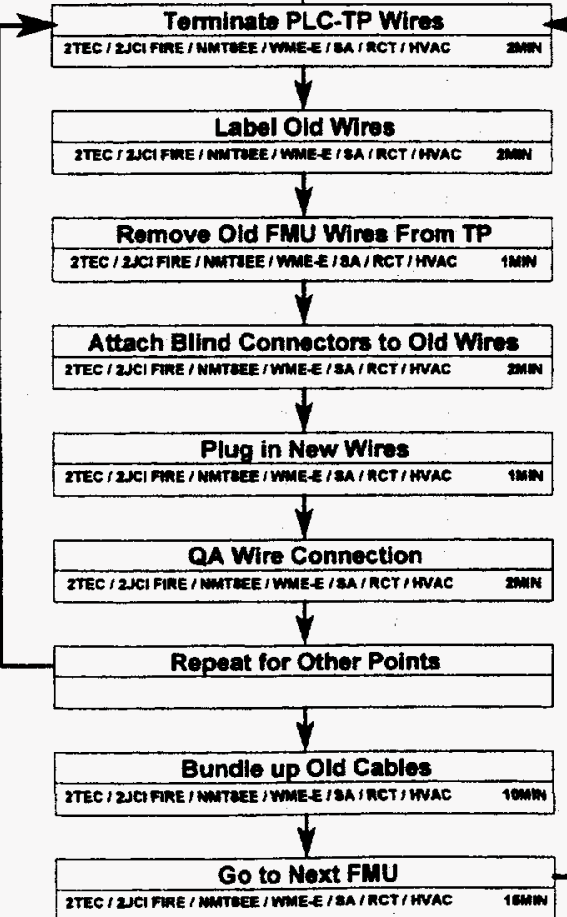

Validate

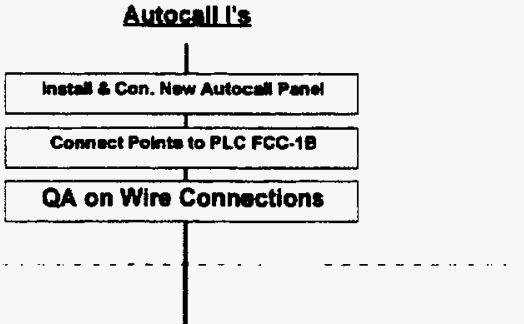

Stert FMU Croseaver

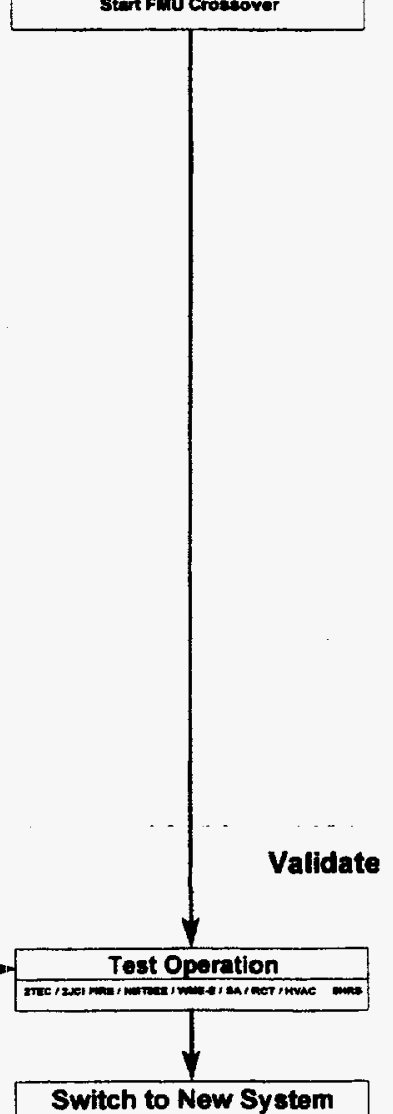

Monzen 11ms

Figure 5. Procedural steps required to crossover fire subsystem. 


\section{FIRE}

\begin{tabular}{|c|}
\hline FMU \#1 (2 LOOPS) \\
\hline$\frac{1}{F M U ~ \# 2 \text { (11 LOOPS) }}$ \\
\hline $\bar{Y}$ \\
\hline FMU $\# 3$ (10 LOOPS) \\
\hline$Y$ \\
\hline FMU $\# 4$ (9 LOOPS) \\
\hline$Y$ \\
\hline FMU $\# 5$ (4 LOOPS) \\
\hline $\bar{y}$ \\
\hline FMU \#6 (12 LOOPS) \\
\hline$Y$ \\
\hline FMU $\$ 7$ (8 LOOPS) \\
\hline$y$ \\
\hline FMU \#9 (2 LOOPS) \\
\hline $\bar{Y}$ \\
\hline FMU \#10 (6 LOOPS) \\
\hline $\bar{y}$ \\
\hline FMU \#11 (3 LOOPS) \\
\hline$y$ \\
\hline FMU \#12 (1 LOOP) \\
\hline 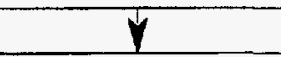 \\
\hline FMU \#13 (11 LOOPS) \\
\hline$Y$ \\
\hline FMU \#15 (1 LOOP) \\
\hline$Y$ \\
\hline FMU \#17 (5 LOOPS) \\
\hline$Y$ \\
\hline FMU \#18 (2 LOOPS) \\
\hline $\bar{y}$ \\
\hline FMU \#19 (10 LOOPS) \\
\hline$y$ \\
\hline FMU \#20 (1 LOOP) \\
\hline
\end{tabular}

Figure 6. Order in which FMUs associated with the fire subsystem will be crossed over.

\section{Identification of Required Personnel.}

\section{Work Crew:}

2 Electronic Technicians (NMT-8)

1 Radiological Control Technician (ESH-1)

2 JCI Fire System Technicians

Number of Crews: 1

Shared Crew:

1 HVAC Engineer (NMT-8)

1 Operations Center System Administrator (NMT-8)

1 Wunderlich-Malec System Engineer

1 Electrical Engineer (NMT-8)
4. Verification Overview. The fire system crossover will be verified by activating test alarms in the BRASS panel and validating alarm status changes in the Operations Center. In addition, fire points in the field that are not associated with the BRASS panel will be individually field tested.

\section{Continuous Air Monitors}

\section{Description of Approach and Work Flow} Analysis. Figure 7 outlines the procedural tasks required to crossover all CAMs. There are 187 CAMs throughout PF-4 which are tied into existing FMUs. (There are a total of 278 CAM units in the inventory). CAMs will be crossed over to PLCs on an FMU-by-FMU basis. Internal CAM wiring must be changed simultaneous to the FMU-to-PLC crossover. The internal wiring change will convert the CAM output signal from a pulsed protocol to a 4$20 \mathrm{~mA}$ protocol. (In designing the new PLC system, inclusion of the pulsed output protocol would have resulted in a slower, less reliable, and more costly data acquisition system. Therefore, new signal transducers are being installed in to each CAM used at TA-55 so that the signal protocol can be switched to an analog output.) The signal protocol switch occurs during this crossover period. Special connectors have been added to each CAM in order to facilitate this switch. In addition, the internal wiring modification allows a digital power indicator to be used to remotely monitor the operational status of each CAM.

Since their are no site audible alarms associated with CAMs, the CAMs crossover does not require any change to the alarm outputs.

FMUs and associated 24 VDC power supplies will remain operational ("hot") during crossover.

Wires from the PLC I/O cards in the FCC cabinets will be "prewired' into the FMU TP prior to the start of the crossover period. This includes the pulling of cables from the FCC to the TP, the cutting and stripping of wires to pre-measured lengths inside the TP, labeling of old TP-FMU cables and positioning of wires using wire ties.

2. Schedule. Figure 8 outlines the order in which FMUs will be worked on. The order was determined by analyzing the number of CAMs interfaced to each FMU and the available work time during a 10-hour shift. Figure 3 shows the schedule for the CAM system crossover with respect to the overall crossover schedule. 


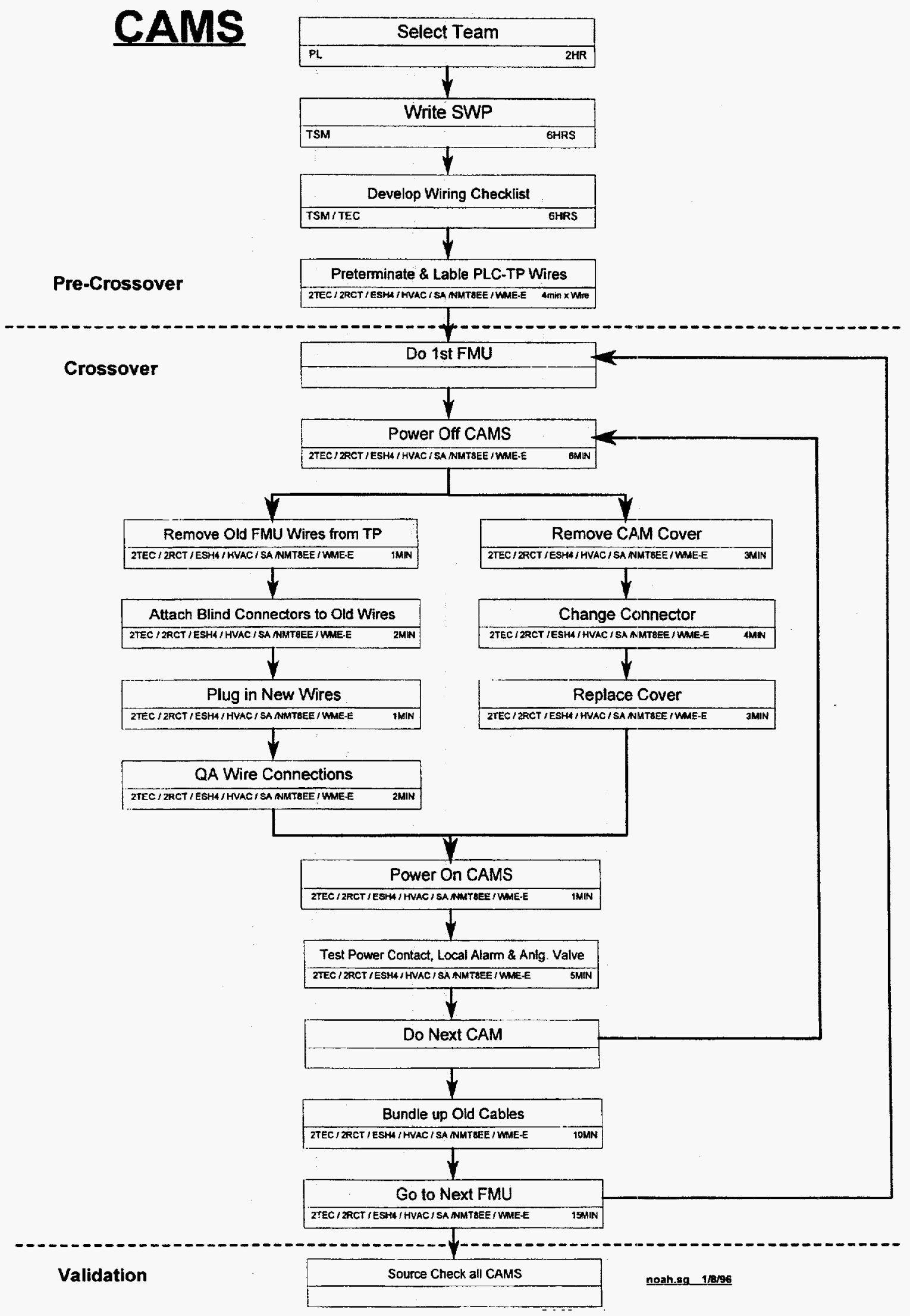

Figure 7. Procedural steps required to crossover CAMs subsystem. 


\section{CAMS}

\section{CREWS}

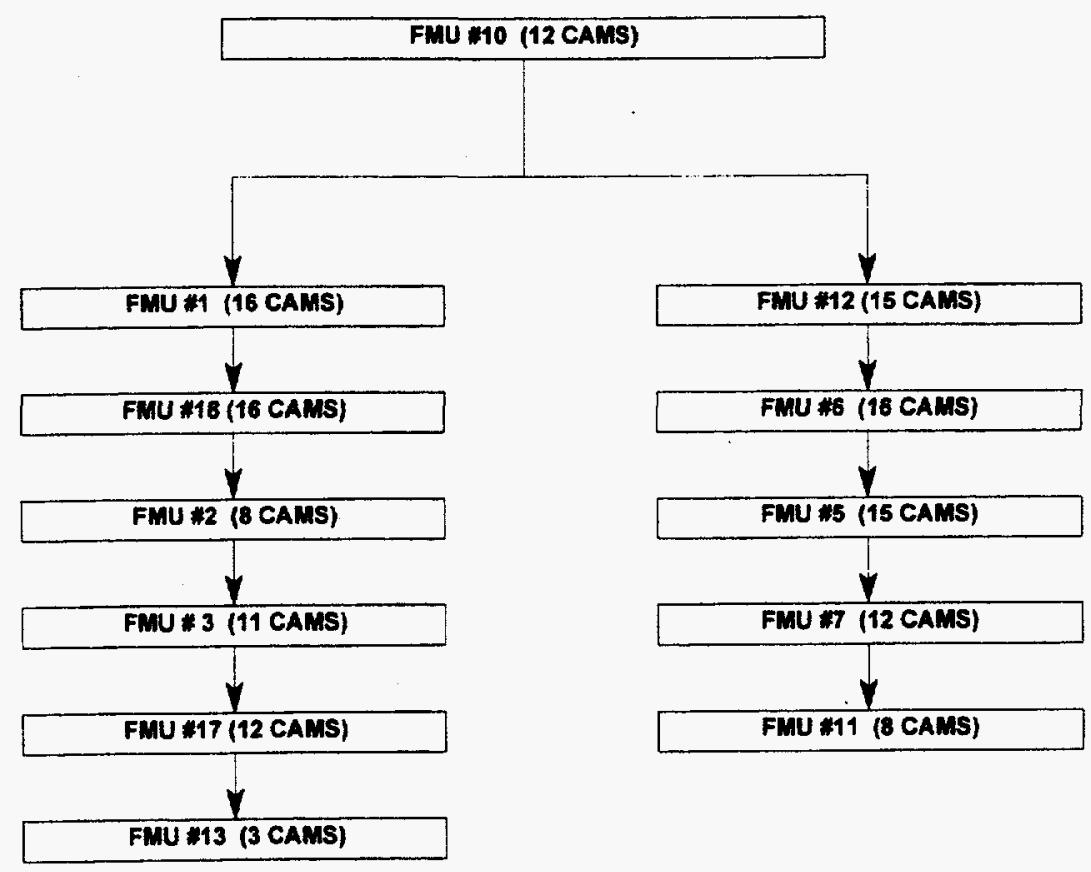

Figure 8. Order in which FMUs associated with the CAM subsystem will be crossed over.

\section{Identification of Required Personnel.}

\section{Work Crew:}

2 Electronic Technicians (NMT-8)

2 Radiological Control Technicians (ESH-1)

1 Radiological Instrumentation Technician (ESH-4)

Number of Crews: 2

Shared Crew:

1 HVAC Engineer (NMT-8)

1 Operations Center System Administrator (NMT-8)

1 Wunderlich-Malec System Engineer

1 Electrical Engineer (NMT-8)

4. Verification Procedures. Each CAM will be tested in the field by activating the manual alarm button on the unit. The following will be tested: (1) high-level field alarm activates; (2) meter is functional; (3) power switch is functional; and (4) all test activity is able to be adequately monitored on the new FCS in the Operation Center. In addition, ESH-1 will perform the standard OSR test upon completion of crossover to certify operational status.

\section{Criticality Alarm System}

\section{Description of Approach and Work Flow} Analysis. Figure 9 outlines the procedural steps involved with the crossover of the criticality alarm system. Twenty criticality detectors located throughout PF-4 provide three signals each into the FMU located in the Operations Center. These signals will be crossed over to the new PLC located in the Operations Center at the same time that the outputs to the audible alarm system are crossed over.

2. Schedule. Figure 3 illustrates the schedule for the crossover of the criticality alarm system with respect to the overall crossover schedule. Only FMU21 is affected by the crossover.

\section{Identification of Required Personnel.}

Work Crew:

2 Electronic Technicians (NMT-8)

3 Radiological Control Technician (ESH-1)

Number of Crews: 1 


\section{CRITICALITY}

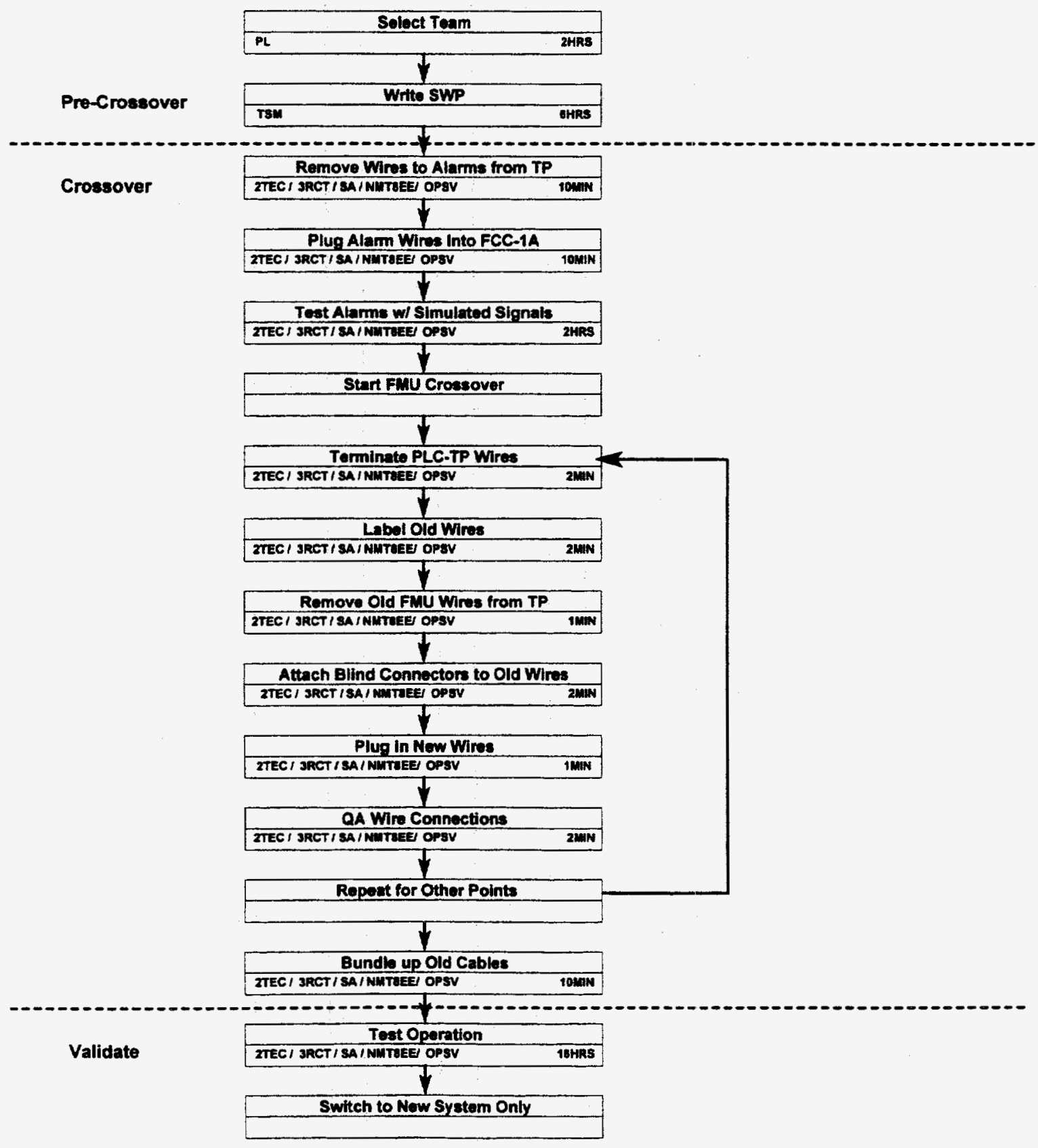

Figure 9. Procedural steps required to crossover criticality alarm subsystem. 


\section{Shared Crew:}

1 Operations Center Supervisor

1 Operations Center System Administrator (NMT-8)

1 Electrical Engineer (NMT-8)

4. Verification Procedures. The criticality alarm system will be verified using the standard OSR procedure. Each criticality alarm sensor will be tested by ESH-1 and NMT-8 using a gamma source and the standard operational test. System response will be verified in the Operations Center.

\section{E. Electrical Switchgear System}

1. Description of Approach and Work Flow Analysis. Figure 10 outlines the procedural tasks involved with the crossover of the electrical switchgear system. There are no automated outputs associated with the switchgear system. Wiring will be crossed over on an FMU-by-FMU basis.

\section{Schedule.}

Figure 3 outlines the relative time frame in which the system will be crossed over. Figure 11 outlines the order in which FMUs will be crossed over.

\section{Identification of Required Personnel.}

Work Crew:

2 Electronic Technicians (NMT-8)

1 Radiological Control Technician (ESH-1)

1 Electrical Engineer (NMT-8)

Number of Crews: 2

Shared Crew:

1 Operations Center System Administrator (NMT-8)

1 Wunderlich-Malec System Engineer

4. Verification Procedures. The electrical switchgear will be tested by comparing the state of the inputs prior to and after crossover to ensure that they are identical.

\section{F. Heating, Ventilation, and Air Conditioning (HVAC)}

\section{Description of Approach and Work Flow} Analysis. Figure 12 outlines the procedural tasks involved with the crossover of the HVAC system. The HVAC portion of the FCS involves control outputs which are required to actuate ventilation fans and other equipment in order to avoid a loss of glovebox negativity. The HVAC system is tied to several FMUs throughout PF-4 and it must function with these and other equipment as a system. Therefore, certain HVAC points, referred to as "Type 2 points," cannot be hooked up piecemeal or as a precrossover activity; they must undergo crossover together and be tested as a single, unified system. Consequently, a two-week continuous period (14 days) is required to perform the HVAC crossover. During this time, PF-4 will be closed to all programmatic work.

Other HVAC points, referred to as "Type 1 points," are primarily informational in nature and are not part of the actual control programs. These can be crossed over individually prior to the two-week stand-down period with little impact to operations. Both types of points are discussed below.

Type 1 Crossover: Type 1 points are described as noncritical in nature and are primarily sensors or indicating lights which are not used to trigger outputs. These will be crossed over to the new system during a maintenance weekend prior to the two-week shutdown. The procedural tasks are outlined in Figure 13.

Type 2 Crossover: Type 2 points are more critical in nature and are used to determine automatic actions such as the control of fans. These will undergo crossover during the two-week PF-4 shutdown. The procedural tasks are outlined in Figure 14.

The PF-4 HVAC system must be specially configured in a safe shutdown configuration during the crossover of the Type 2 points. A detailed procedure for this is under development by NMT-8 which will include the shutdown of many of the system fans and re-balancing of airflows and pressures throughout PF-4. The safe shutdown will require approximately 2 days to perform, but will leave the plant in a condition which will allow equipment to be powered off prior to crossover to the PLCs. The actual Type 2 crossover will require approximately 510 -hour days. An additional 7 days will be used to test the system implementation and observe that the new system is stable.

2. Schedule. Figure 3 outlines the relative time frame in which the system will be crossed over. Figures 15 and 16 outline the order in which FMUs will be crossed over for Type 1 and Type 2 points, respectively. Type 1 points will be crossed over on a maintenance weekend prior to the two-week PF-4 shutdown. 


\section{SWITCH GEAR}

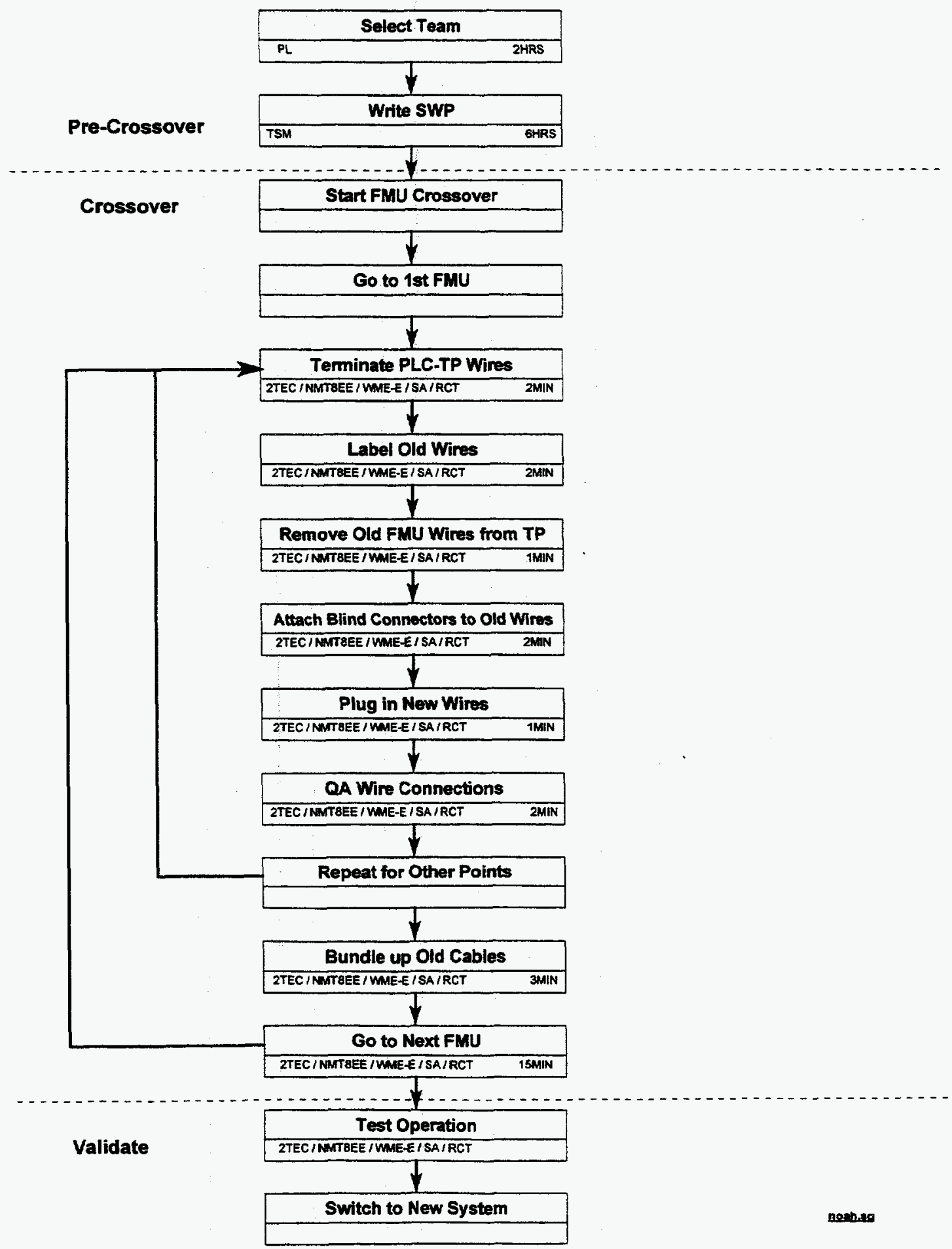

Figure 10. Procedural steps required to crossover electrical switchgear subsystem. 


\section{SWITCHGEAR \\ 2 CREWS}

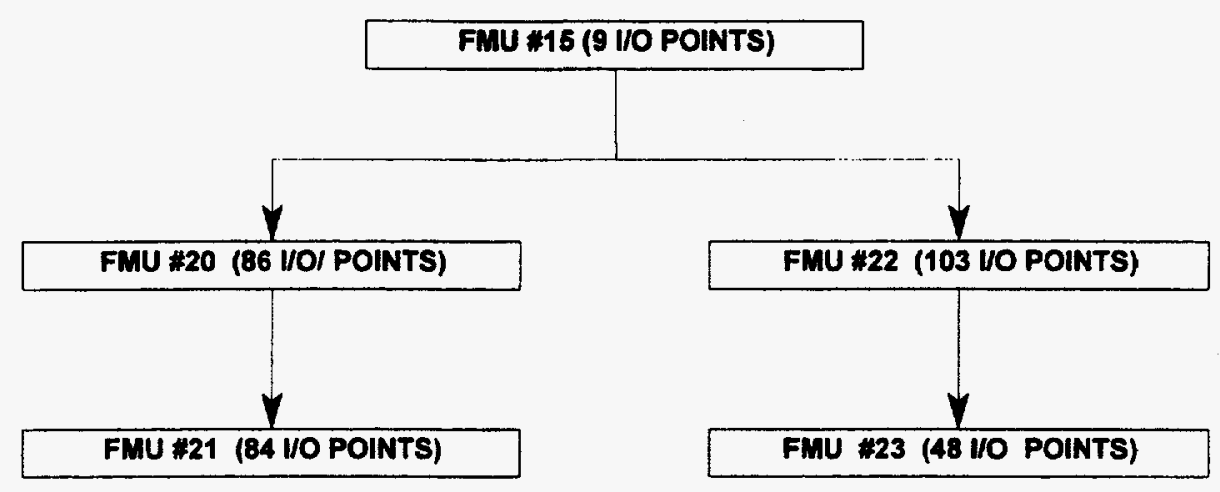

Figure 11. Order in which FMUs associated with the electrical switchgear subsystem will be crossed over. 


\section{HVAC}

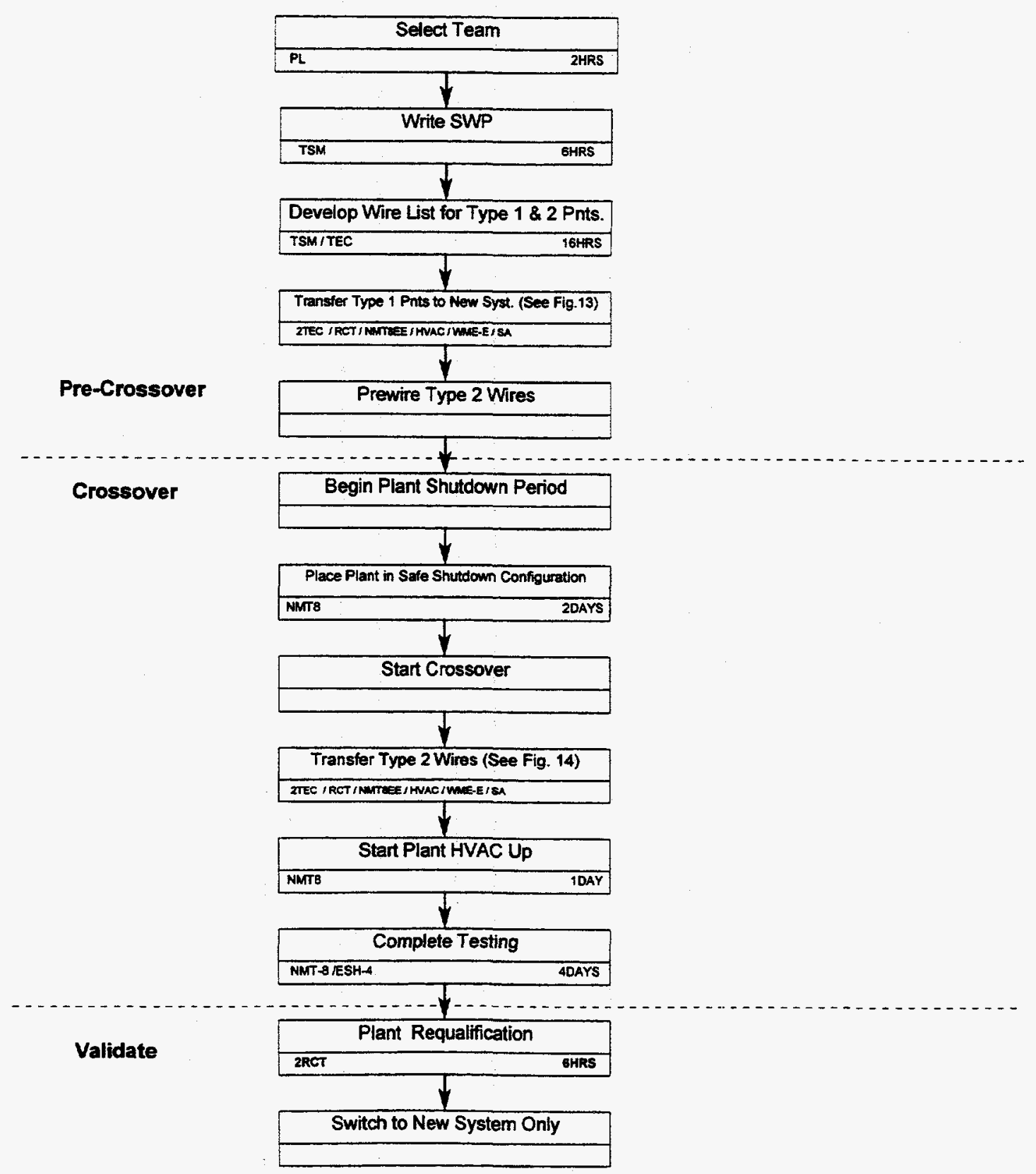

Figure 12. Procedural steps required to crossover HVAC subsystem. 


\section{HVAC}

\section{Detail A: Crossover Type 1 Wires}

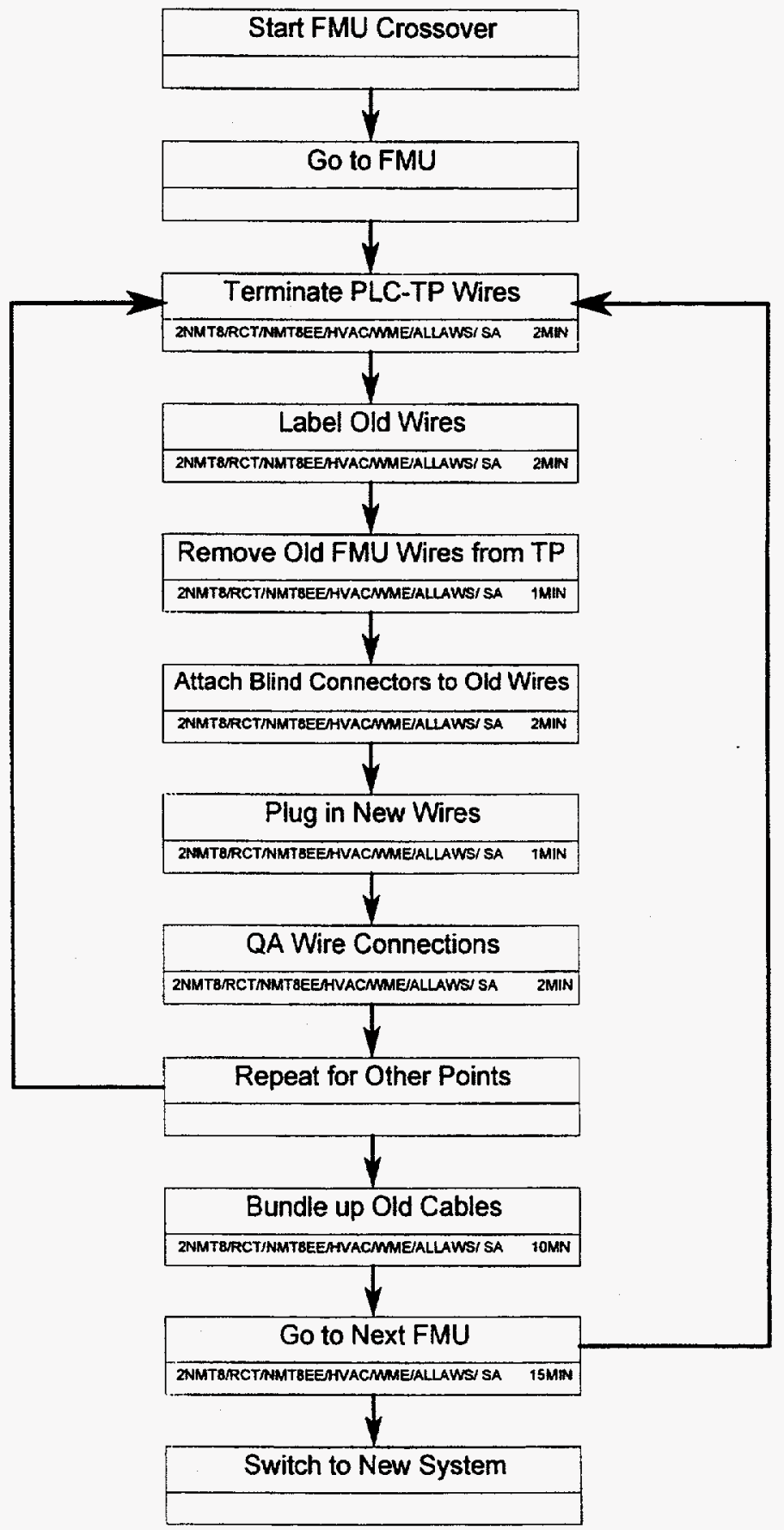

Figure 13. Procedural steps required to crossover Type l points for the HVAC subsystem. 


\section{HVAC \\ Detail B: Crossover Type 2 Wires}

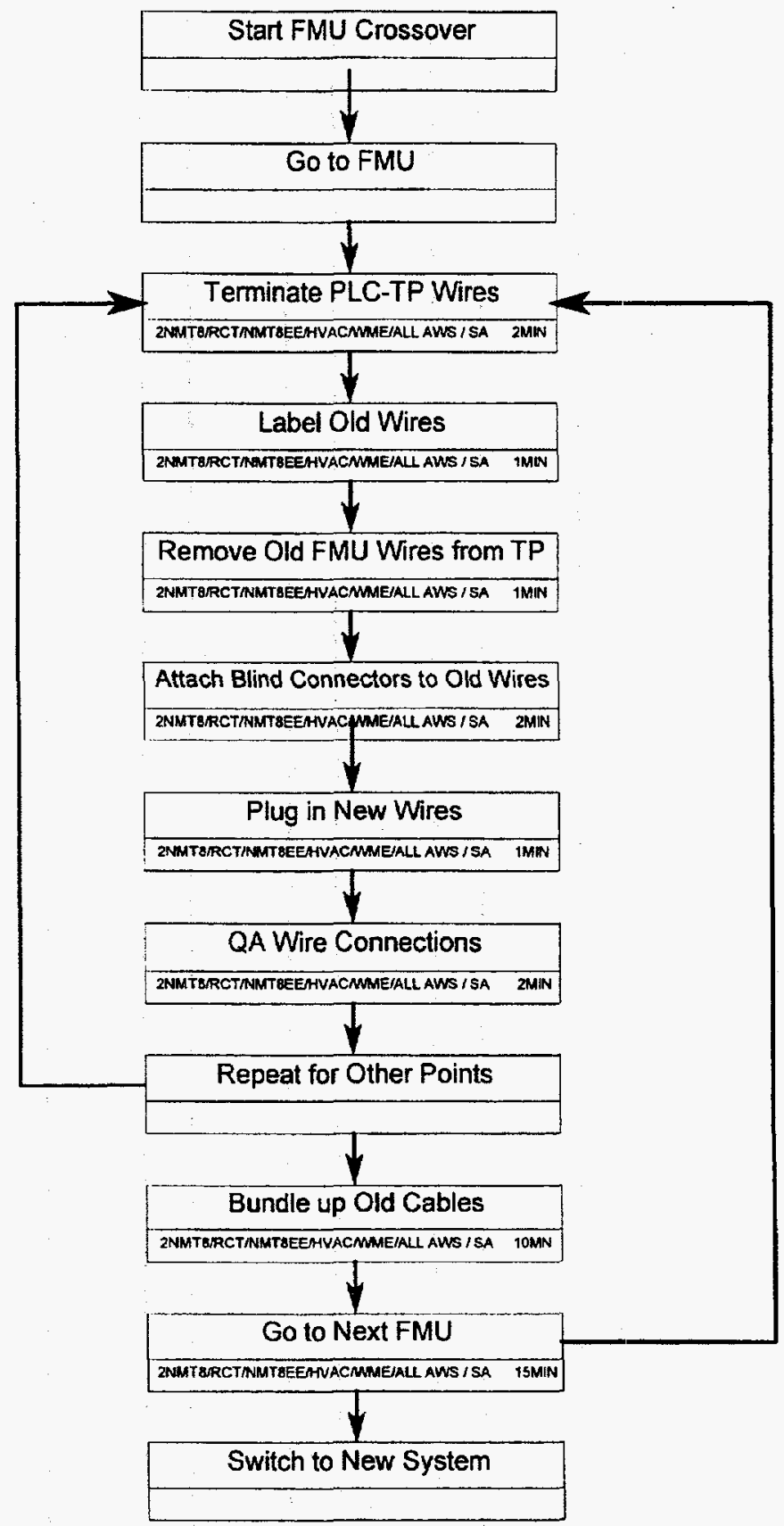

Figure 14. Procedural steps required to crossover Type 2 points for the HVAC subsystem. 


\section{HVAC TYPE 1}

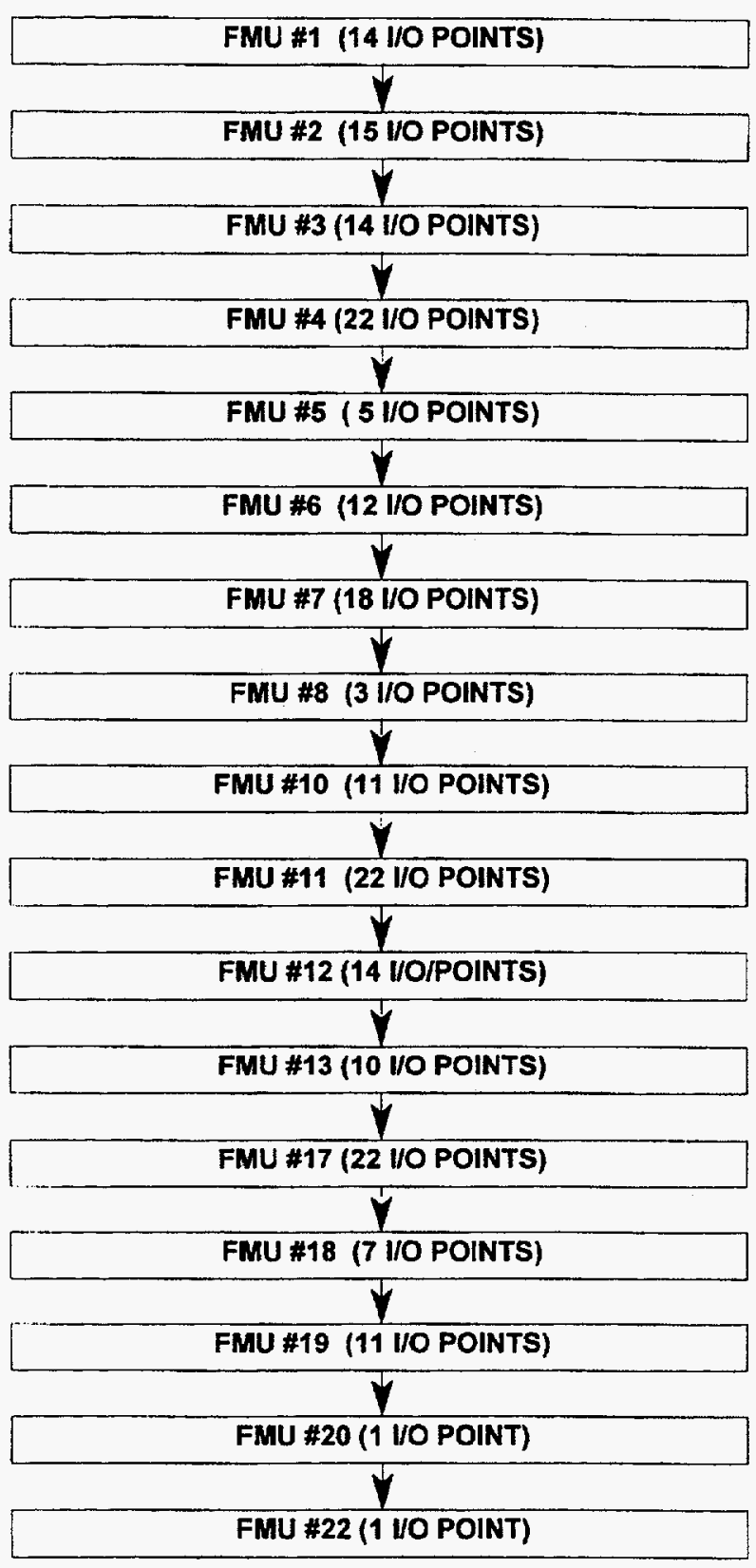

Figure 15. Order in which FMUs associated with the HVAC Type 1 points for the HVAC subsystem will be crossed over.

\section{HVAC TYPE 2}

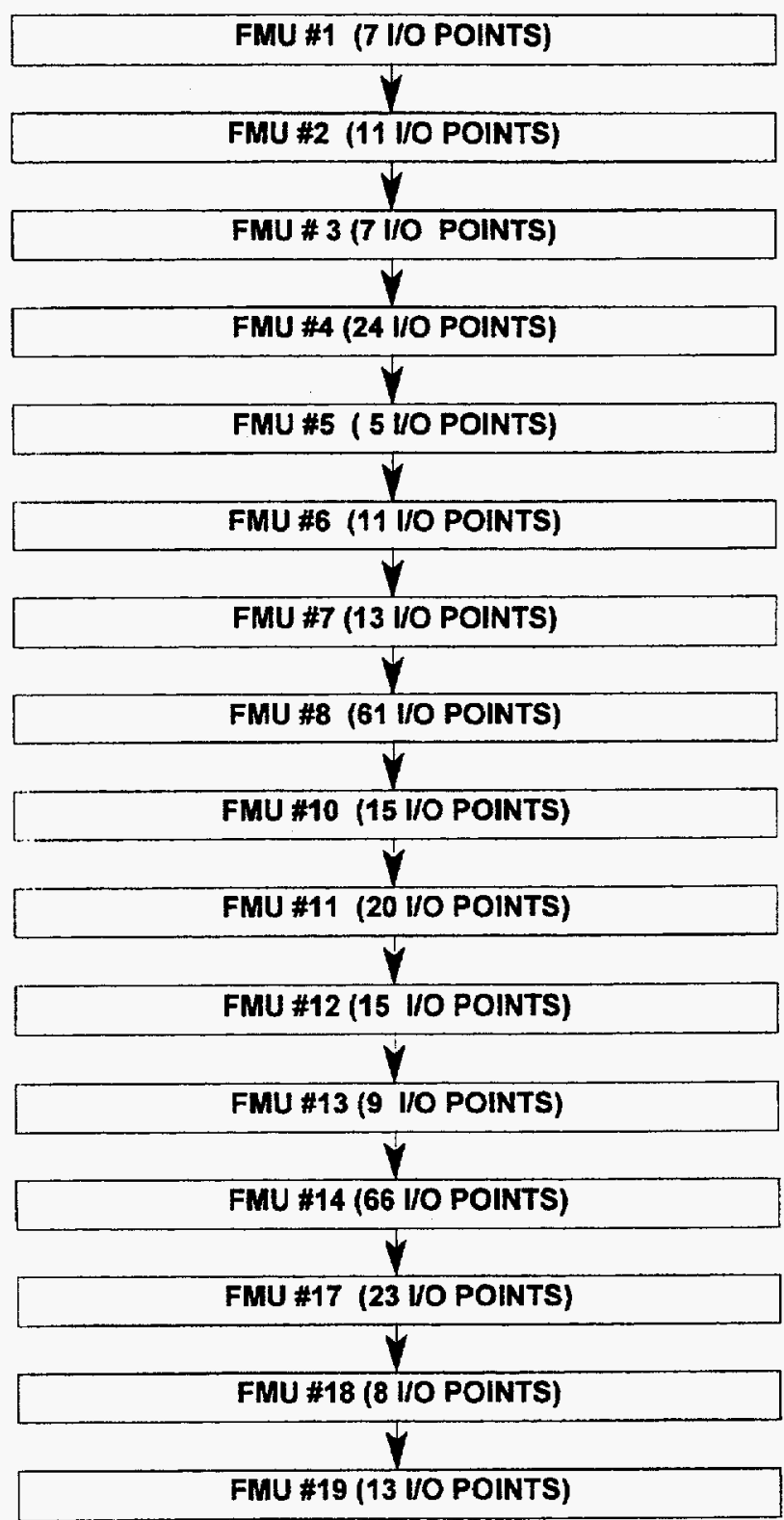

Figure 16. Order in which FMUs associated with the HVAC Type 2 points for the HVAC subsystem will be crossed over. 


\section{Identification of Required Personnel.}

\section{For Type 1 Crossover:}

\section{Work Crew:}

2 Electronic Technicians (NMT-8)

1 Radiological Control Technician (ESH-1)

1 Electrical Engineer (NMT-8)

Number of Crews: 2

Shared Crew:

1 HVAC Engineer (NMT-8)

1 Operations Center System Administrator (NMT-8)

1 Wunderlich-Malec System Engineer

For Type 2 Crossover:

Work Crew:

2 Electronic Technicians (NMT-8)

1 Radiological Control Technician (ESH-1)

1 Electrical Engineer (NMT-8)

Number of Crews: 2

Shared Crew:

1 HVAC Engineer (NMT-8)

1 Operations Center System Administrator (NMT-8)

1 Wunderlich-Malec System Engineer

4. Verification Procedures. The HVAC system will be tested according to the standard operability surveillance procedures normally conducted by NMT-8. In addition, an acceptance test will be written to validate all sensors and relays.

\section{PERSONNEL RESOURCE ANALYSIS}

Total personnel resources have been estimated for all tasks and are outlined as a function of time in Figure 17.

\section{Project Management Overview}

The purpose of these project management schedule presentations is to familiarize the reader with the detailed planning which is going into the development of the Operations Center Upgrade Implementation planning. Included in this detailed planning are the work scheduling, resource allocation and management, and time-phased logic and labor cost projections.

As described throughout this plan, the upgrade is made up of a series of modifications to each of the major facility systems, (fire, criticality, CAMs, switchgear, and HVAC). In order to accurately plan for the necessary scheduling and resource requirements for implementing these modifications, each subsystem was assessed independently. The approach in conducting the estimate was to develop a recurring "loop" of modification tasks to be performed within each system. The fundamental tasks within these loops have already been illustrated in Figures 5 (fire), 7 (CAMs), 9 (criticality), 10 (switchgear), and 12 (HVAC). Starting with estimating the time and resources required for each loop, we extrapolated individual loop durations and resources into FMU requirements. Next, we arrived at the necessary duration and resources for each system crossover. This is then used to select the appropriate calendar time (in conjunction with planned maintenance periods) where each subsystem would undergo crossover.

Appendix A consists of the following Project Management schedules and graphics.

Chart A. Implementation Schedule Summary (by subsystem). This depicts a duration schedule summarizing the total time required to execute an individual loop (consisting of multiple tasks) for that specific subsystem (such as the fire system). This graphic also demonstrates the sequential relationship among tasks and how the process flow of tasks occurs. This view is similar to Figures $5,7,9,10$ and 12 but includes the perspective of time flow.

Chart B. Implementation Schedule - FMU Detail (by subsystem). This illustrates the schedule for performing the task loop for individual FMUs for that system.

Chart $C$. Subsystem Time-phased Logic Diagram. This graphic is the same network of tasks shown in Chart A "Implementation Schedule Summary" only depicted in a standard time-phased logic presentation. This has been provided for those readers who may prefer this format to the Gantt presentation format of Chart A. This diagram simply shows what tasks occur and in what sequence for a single loop of the subsystem crossovers.

After the individual systems are presented, Appendix A moves on to include depictions of schedules and resource requirements for the integration of the numerous subsystem crossovers.

Chart D. Proposed Subsystem Implementation Schedule. This schedule depicts the proposed crossover schedule showing the planned dates by which each subsystem is to undergo crossover as well as the individual (labor) resource skills (by hours) which will be required (by day) to perform the crossovers. 


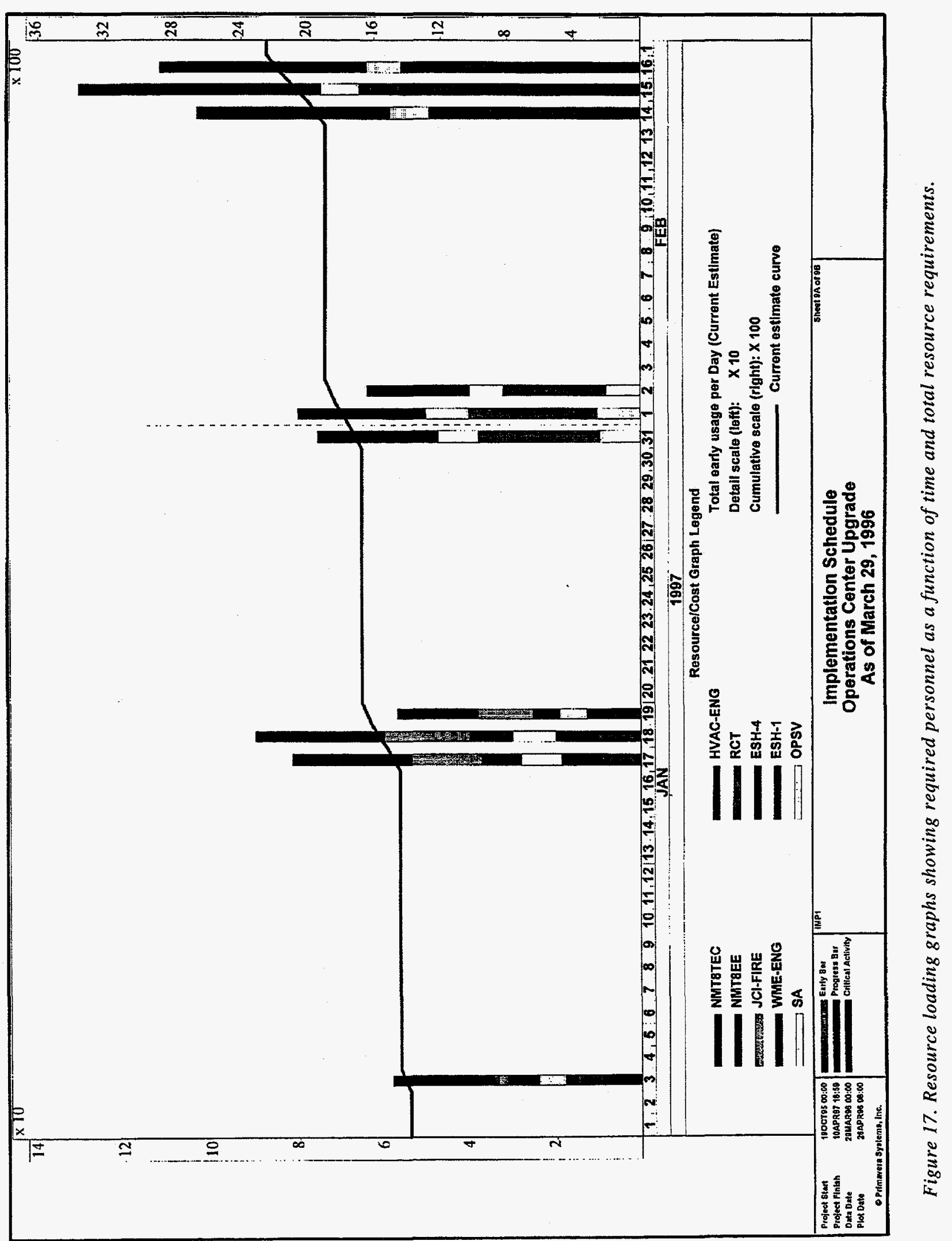




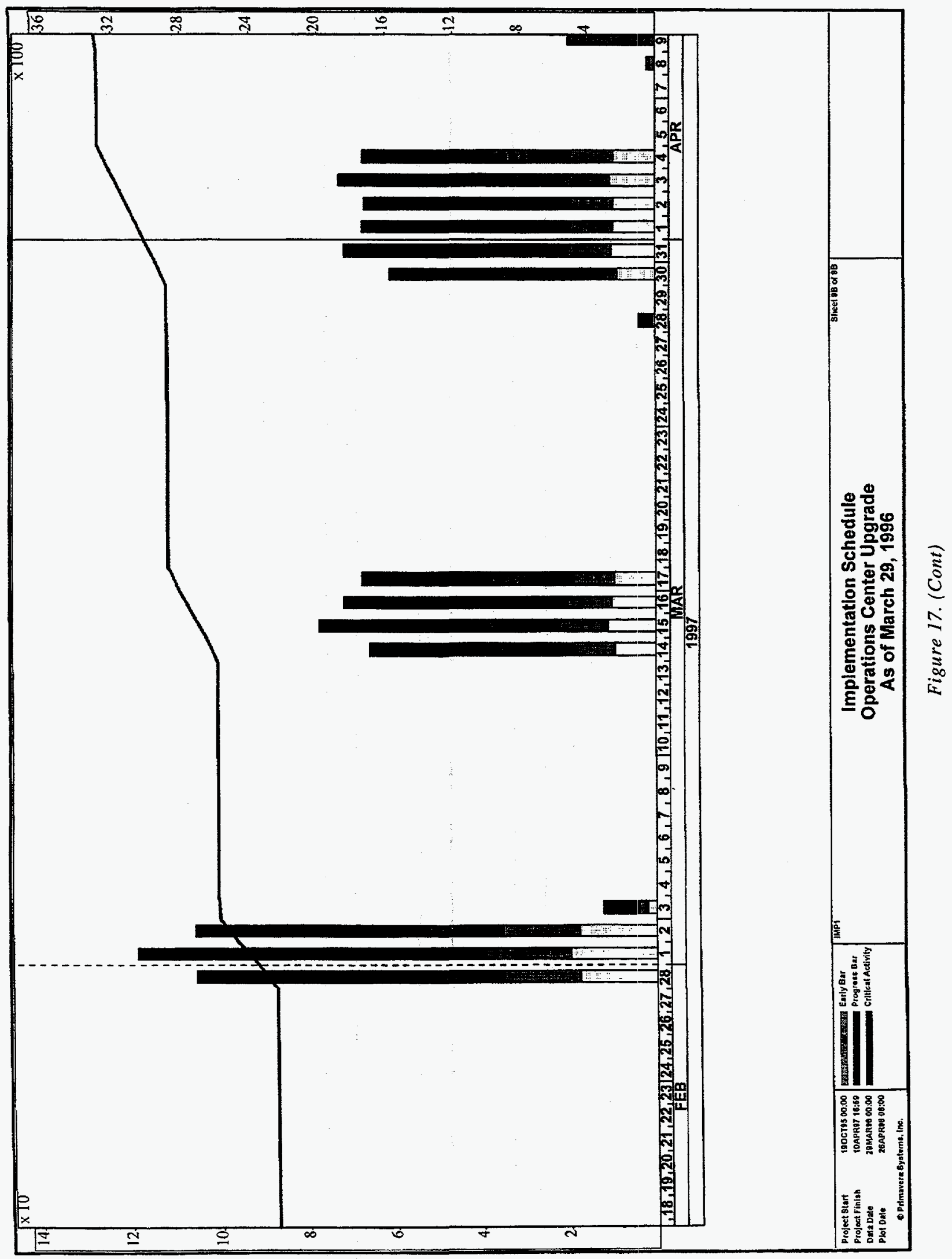




\section{SUMMARY}

Plans to crossover facility instrumentation from the old FCS to the new FCS have been developed in detail, including impact on normal operations in PF-4 and personnel. The purpose of this report has been to detail specific crossover activities, including task start and finish dates, in order for all TA-55 organizations to plan alternative work schedules during this period.

As detailed in the report, most crossover activities will occur during four-day "maintenance" weekends, during which time PF-4 must be reserved solely for these activities. In addition, the crossover of the
HVAC will require a two-week period during which all regular material processing work in PF-4 must stand down. The dates of these events are summarized as follows:

The percentage of points connected to both the old and new FCS system are plotted as a function of time in Figure 18. The intent of the implementation schedule is to allow normal PF-4 operations between maintenance weekends.

The estimates of task duration and schedule are subject to change as work progresses. Although the order in which crossover tasks may change, all effort will be made to complete work during these scheduled times.

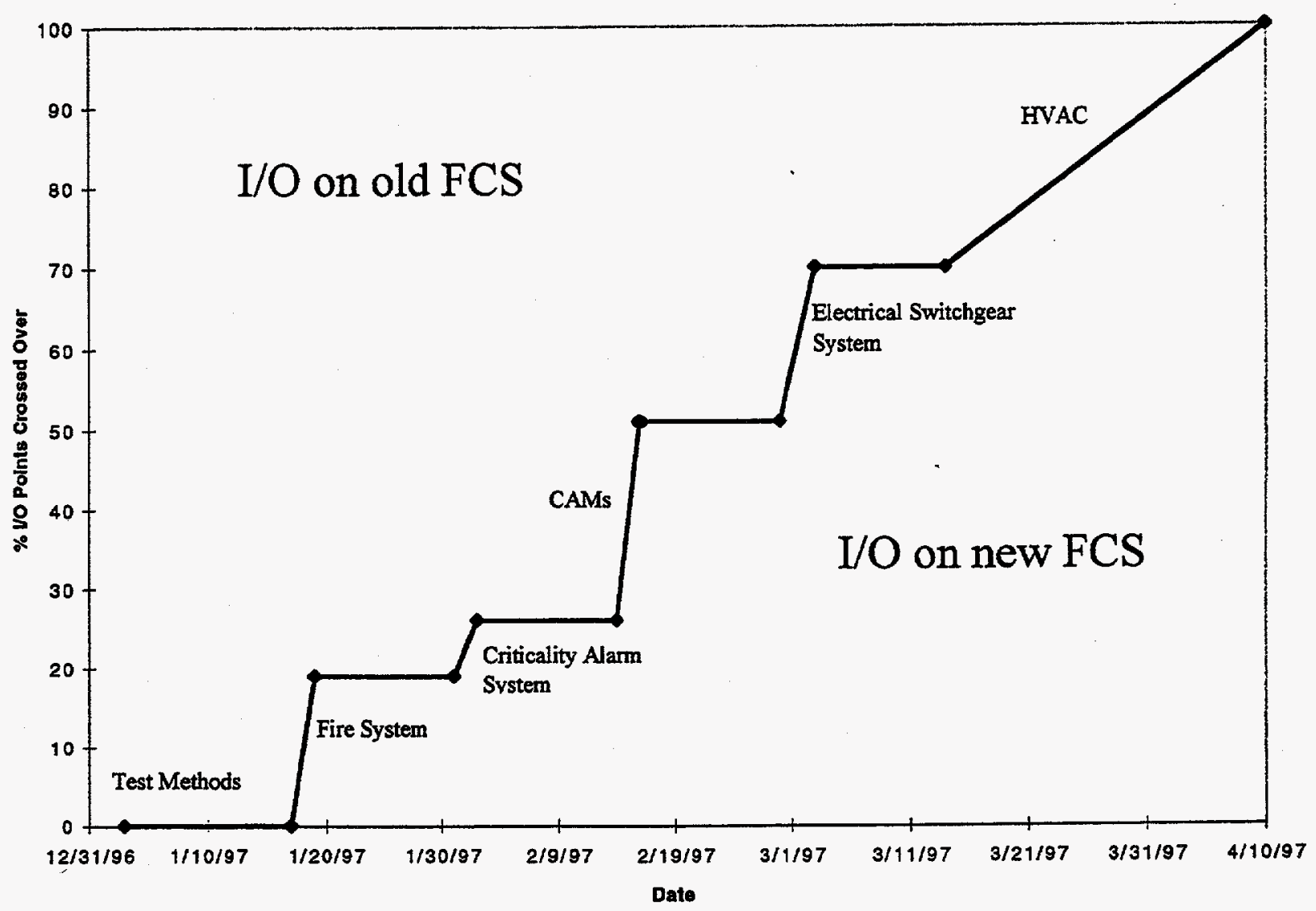

Figure 18. Percentages of $I / O$ points connected to the old and new FCS systems as a function of time. 


\section{REFERENCES}

1. ICF Kaiser Engineering, "Engineering Study for the TA-55 Operations Center Upgrade Facilities Data Acquisition Interface System at the Los Alamos National Laboratory," PI \# 16195, February 22, 1995.

2. Pope, N. G., Turner, W. J., and Brown, R., "TA-55 Facility Control System Upgrade - Facility Data Acquisition Interface System Functional and Operational Requirements," Los Alamos National Laboratory report LA-12914 (May 1995).

3. ICF Kaiser Engineering, "TA-55 Operations Center Upgrade - Facilities Data Acquisition Interface System," Title II Definitive Design Document (September 1995).

4. Turner, W. J., Pope, N. G., and Brown, R. E., "Reliability Analysis for the Facility Data Acquisition Interface System Upgrade at TA-55," Los Alamos National Laboratory report LA-12938 (May 1995).

5. Atkins, W. H., Pope, N. G., Turner, W. J., and Brown, R. E., "TA-55 Facility Control System
Upgrade Human-System Interface Functional Requirements," Los Alamos National Laboratory report LA-13024 (August 1995).

6. Nekimken, N., Pope, N. G., Macdonald, J., Bibeau, R., Gornez, B., Sellon, D., "Evaluation of Human-Machine Interface (HMI) Software," Los Alamos National Laboratory report LA-CP-95-78 (July 1995).

7. Holt, R., Hiller, D., Brown, R. E., Pope, N. G., and Turner, W. J., "TA-55 Facility Control System Software Requirements Specification," Los Alamos National Laboratory report LA-13046-MS (October 1995).

8. ICF Kaiser Engineering, "PF-4 Room 218 Renovation," PI\# 16918, Task 41552-079, December 22, 1995.

9. Pope, N. G., S. Taylor, Brown, R. E., and Turner, W. J., "Test and Acceptance Plan for the Upgrade of the TA-55 Facility Control System," Los Alamos National Laboratory report (in progress). 


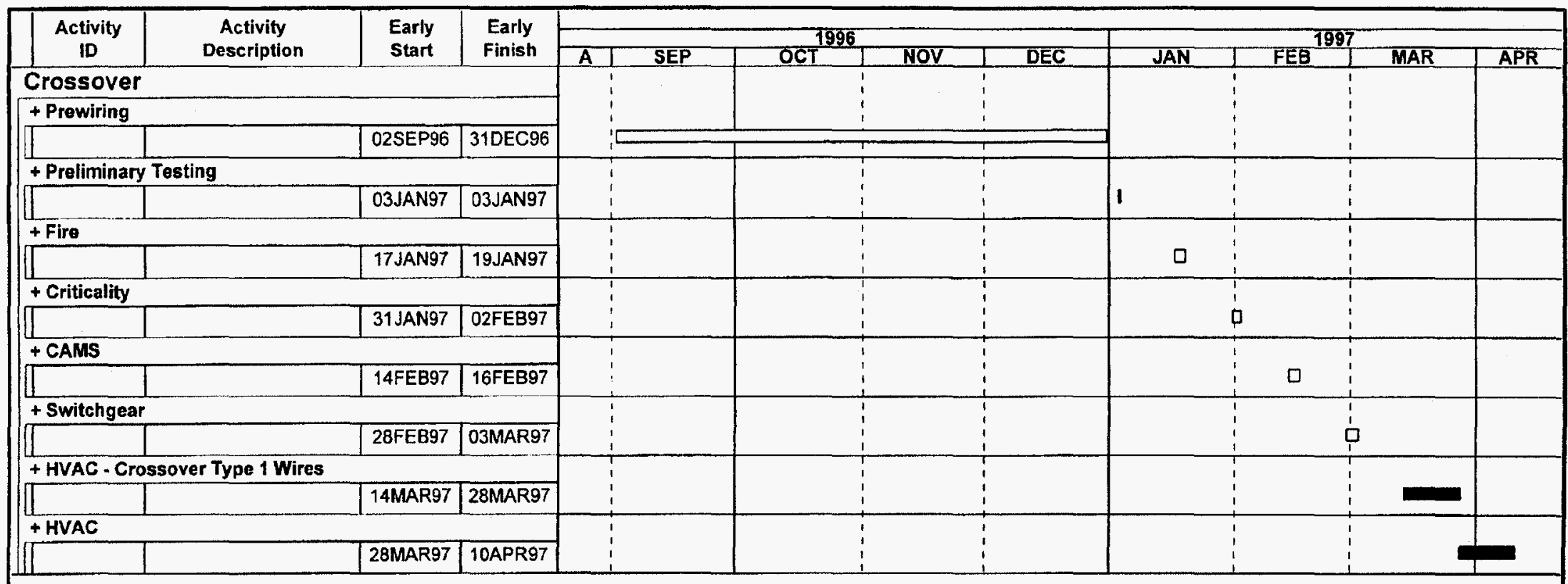

\begin{tabular}{|c|c|c|}
\hline 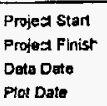 & 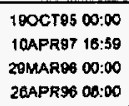 & $\begin{array}{l}\square \\
\\
\end{array}$ \\
\hline \multicolumn{2}{|c|}{ OPrimavara Systems, inc. } & \\
\hline
\end{tabular}




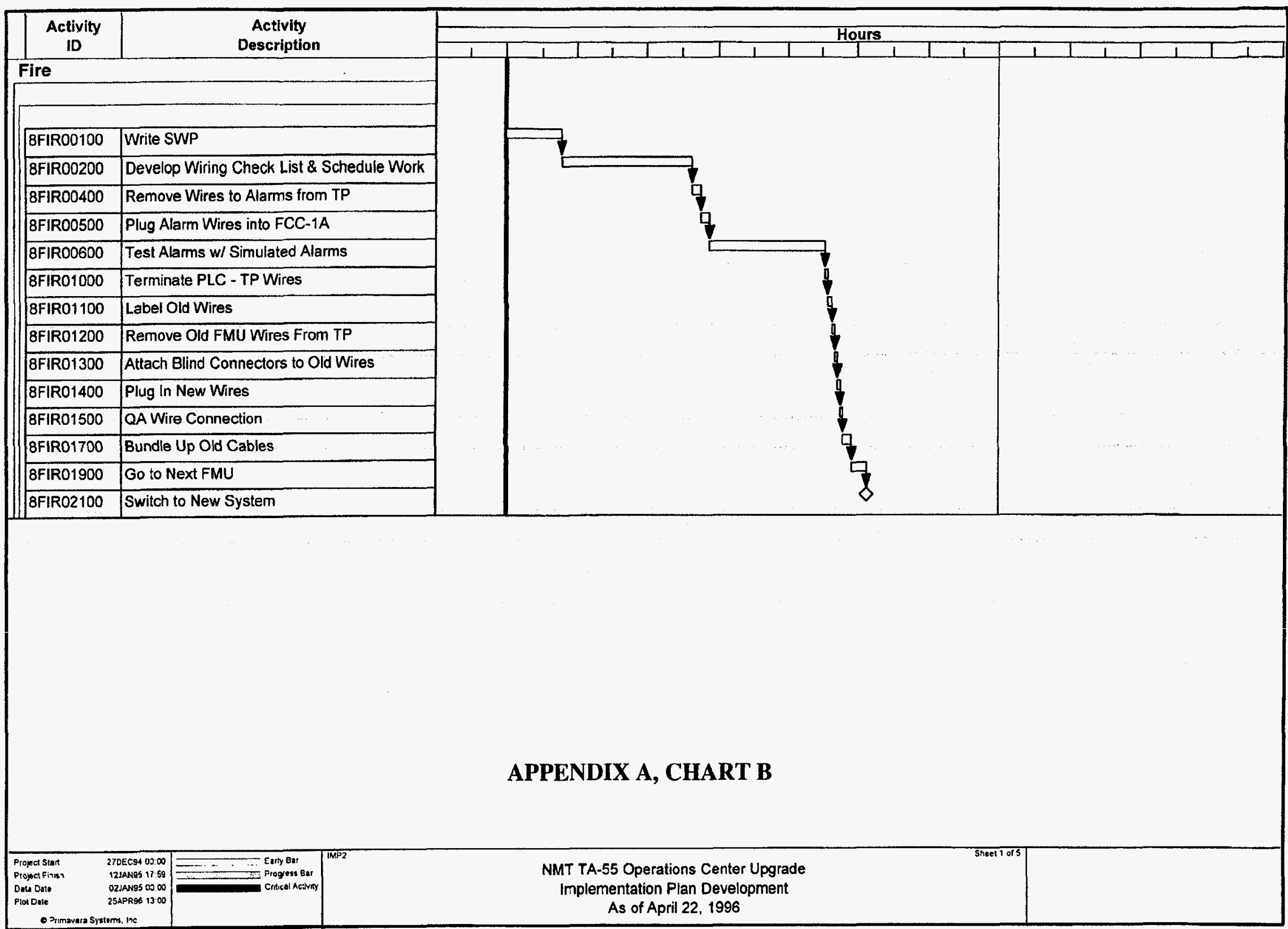




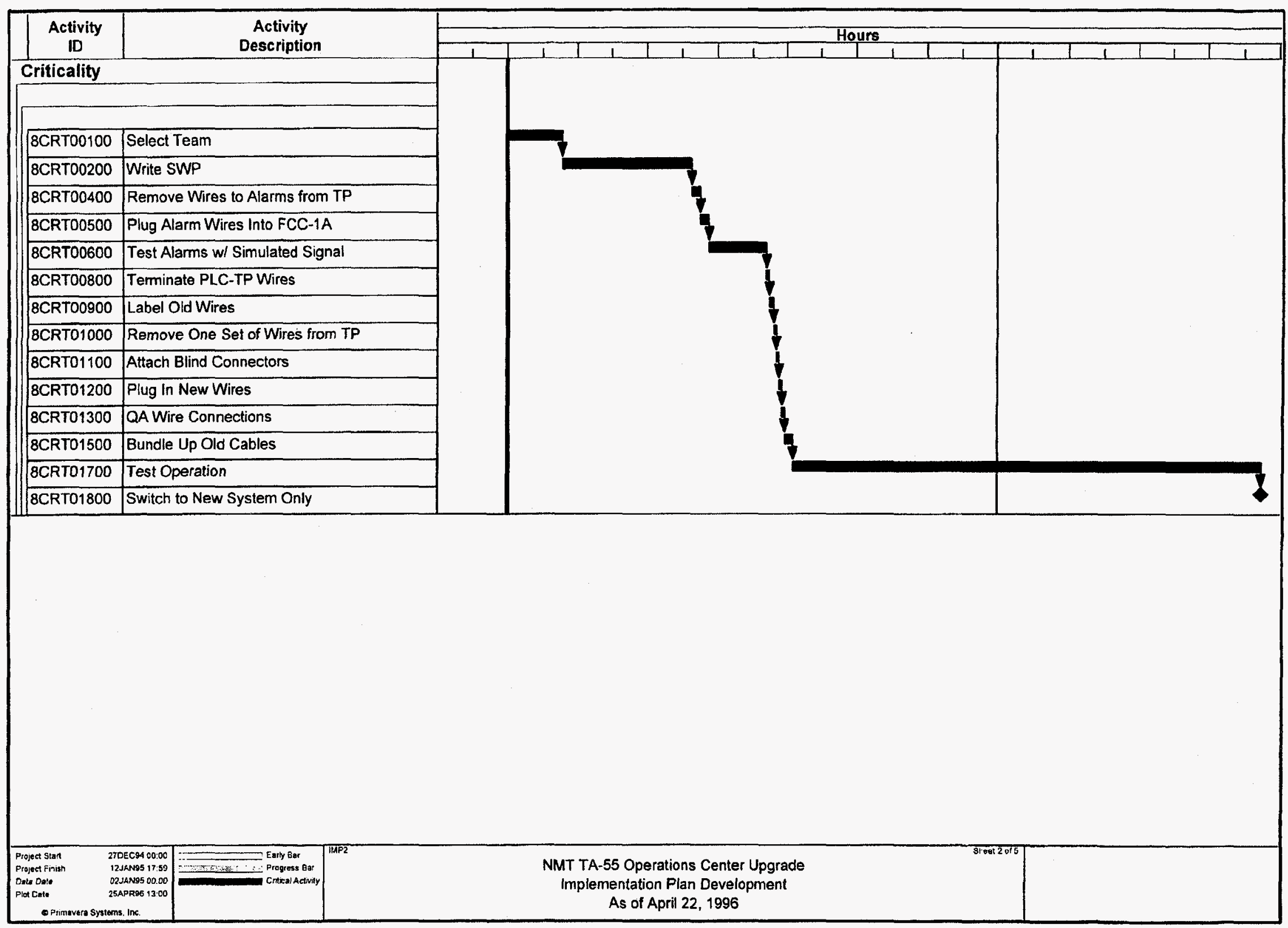




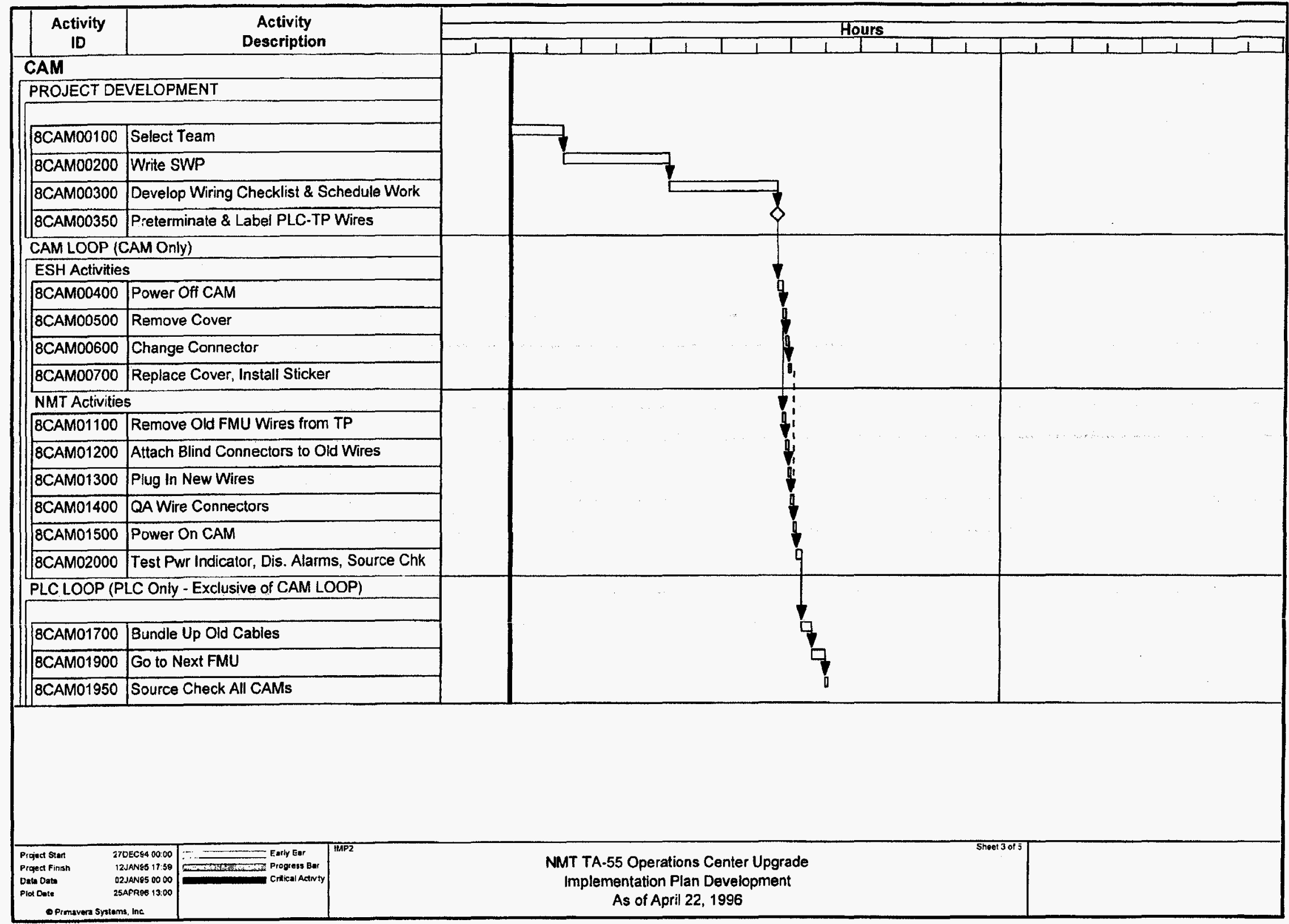




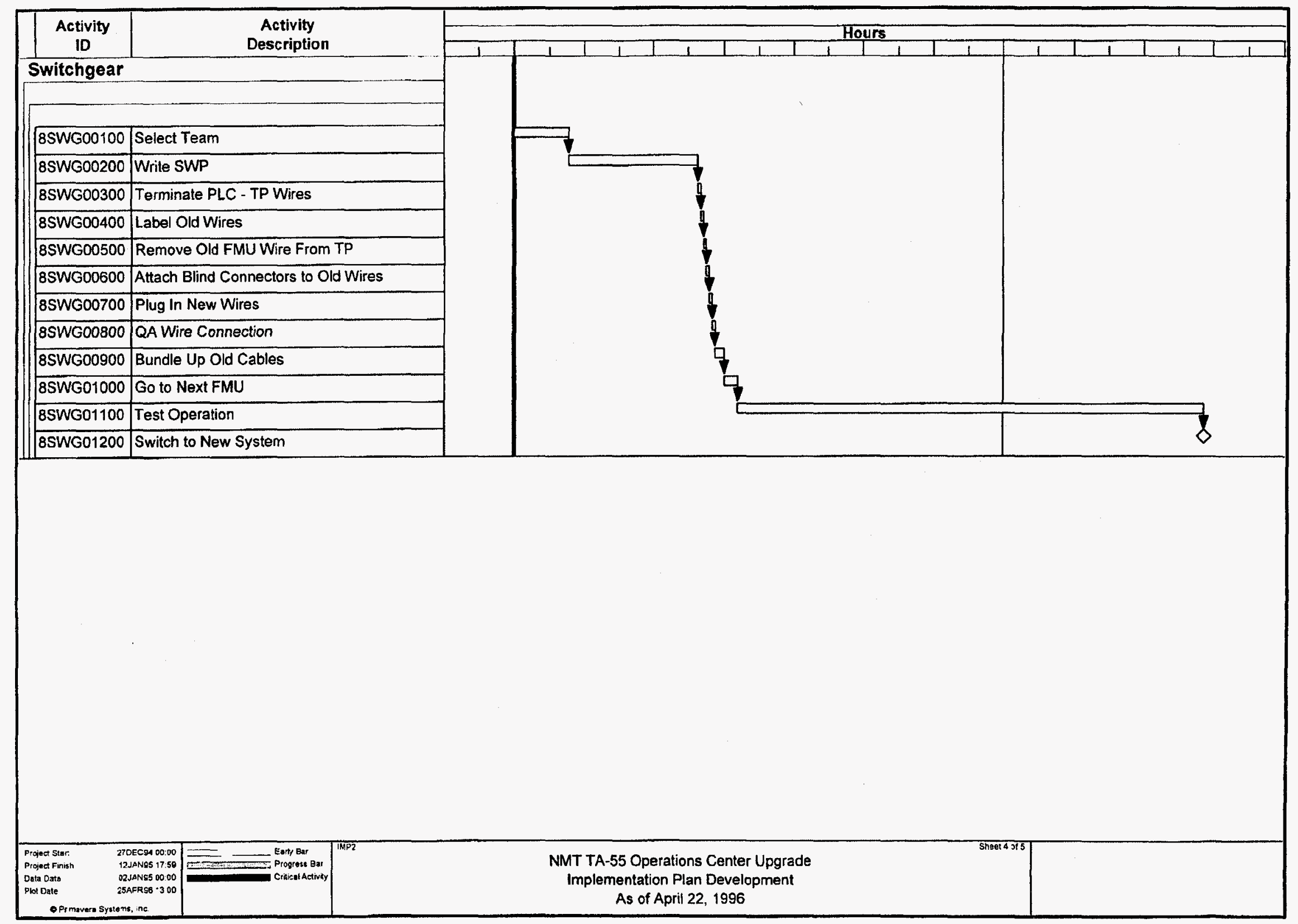




\begin{tabular}{|c|c|c|c|}
\hline $\begin{array}{l}\text { Activity } \\
\text { ID }\end{array}$ & $\begin{array}{l}\text { Activity } \\
\text { Description }\end{array}$ & Hours & \\
\hline HVAC & & & \\
\hline & - & & \\
\hline $8 \mathrm{HVC} 00100$ & Select Team & 7 & \\
\hline $8 \mathrm{HVC} 00200$ & Write SWP & & \\
\hline $8 \mathrm{HVC} 00300$ & Develop Wire List for Type 1 \& Type 2 Points & & \\
\hline $8 \mathrm{HVC} 00350$ & Start Type 1 Wires & & \\
\hline $8 \mathrm{HVC} 00400$ & Terminate PLC - TP Wires & & \\
\hline $8 \mathrm{HVC00500}$ & Label Old Wires & & \\
\hline $8 \mathrm{HVCO} 00600$ & Remove Old FMU Wire From TP & & \\
\hline $8 \mathrm{HVC00700}$ & Attach Blind Connectors to Old Wires & & \\
\hline $8 \mathrm{HVC} 00800$ & Plug - In New Wires & & \\
\hline $8 \mathrm{HVC} 00900$ & QA Wire Connection & & \\
\hline $8 \mathrm{HVCO} 01000$ & Bundle-Up Old Cables & & \\
\hline $8 \mathrm{HVC} 01100$ & Goto Next FMU & & \\
\hline $8 \mathrm{HVC01200}$ & Prewire Type 2 Wires & & \\
\hline $8 \mathrm{HVC} 01300$ & Place Plant in Safe Shutdown Configuration & & \\
\hline $8 \mathrm{HVC} 01400$ & Start Type 2 Wires & & \\
\hline $8 \mathrm{HVC} 01500$ & Terminate PLC - TP Wires & & \\
\hline $8 \mathrm{HVC} 01600$ & Label Old Wires & & \\
\hline $8 \mathrm{HVC} 01700$ & Remove Old FMU Wire From TP & & \\
\hline BHVC01800 & Attach Blind Connectors to Old Wires & & \\
\hline $8+\mathrm{HVC01900}$ & Plug In New Wires & & \\
\hline $8+\mathrm{HVC} 02000$ & QA Wire Connection & & \\
\hline $8 \mathrm{HVC} 02100$ & Bundle Up Old Cables & & \\
\hline $8 \mathrm{HVC02200}$ & Go to Next FMU & 7 & \\
\hline $8 \mathrm{HVC} 02300$ & Start Plant HVAC Up & & \\
\hline $8 \mathrm{HVC} 02400$ & Switch Over to New System & & \\
\hline 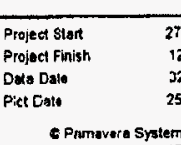 & 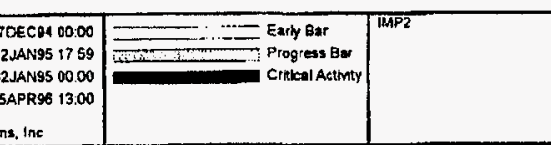 & $\begin{array}{l}\text { NMT TA-55 Operations Center Upgrade } \\
\text { Implementation Plan Development } \\
\text { As of Appril 22, } 1996\end{array}$ & \\
\hline
\end{tabular}




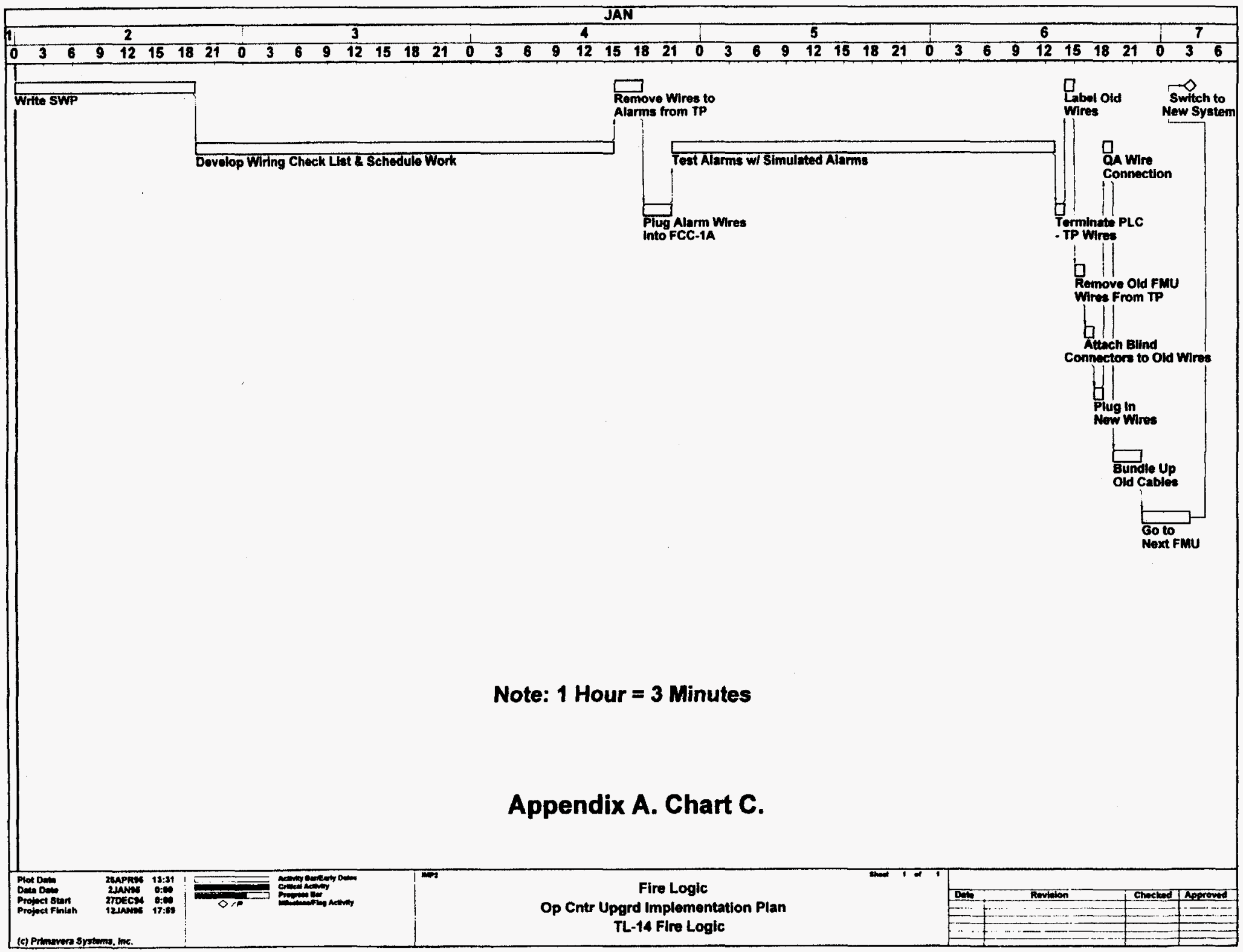




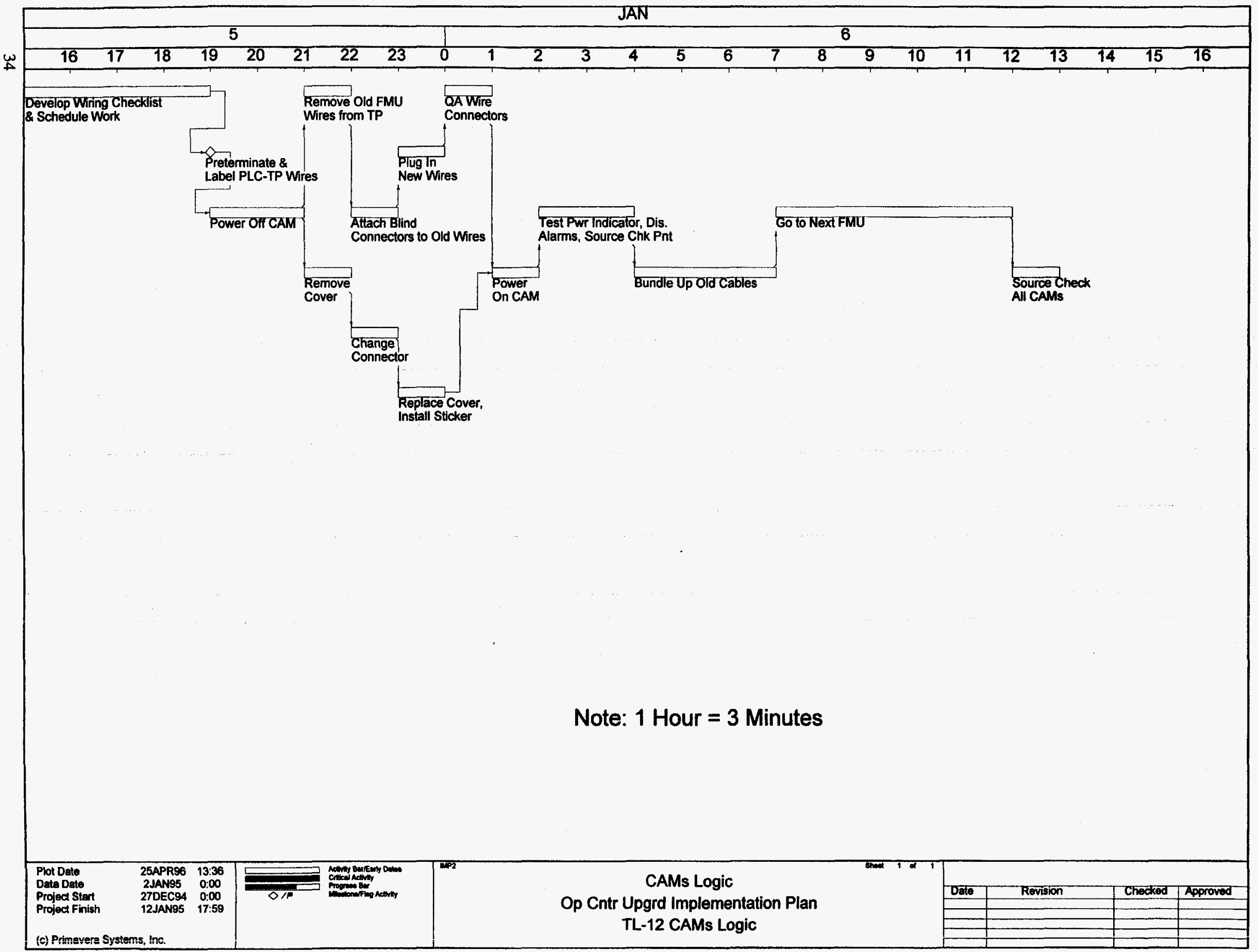




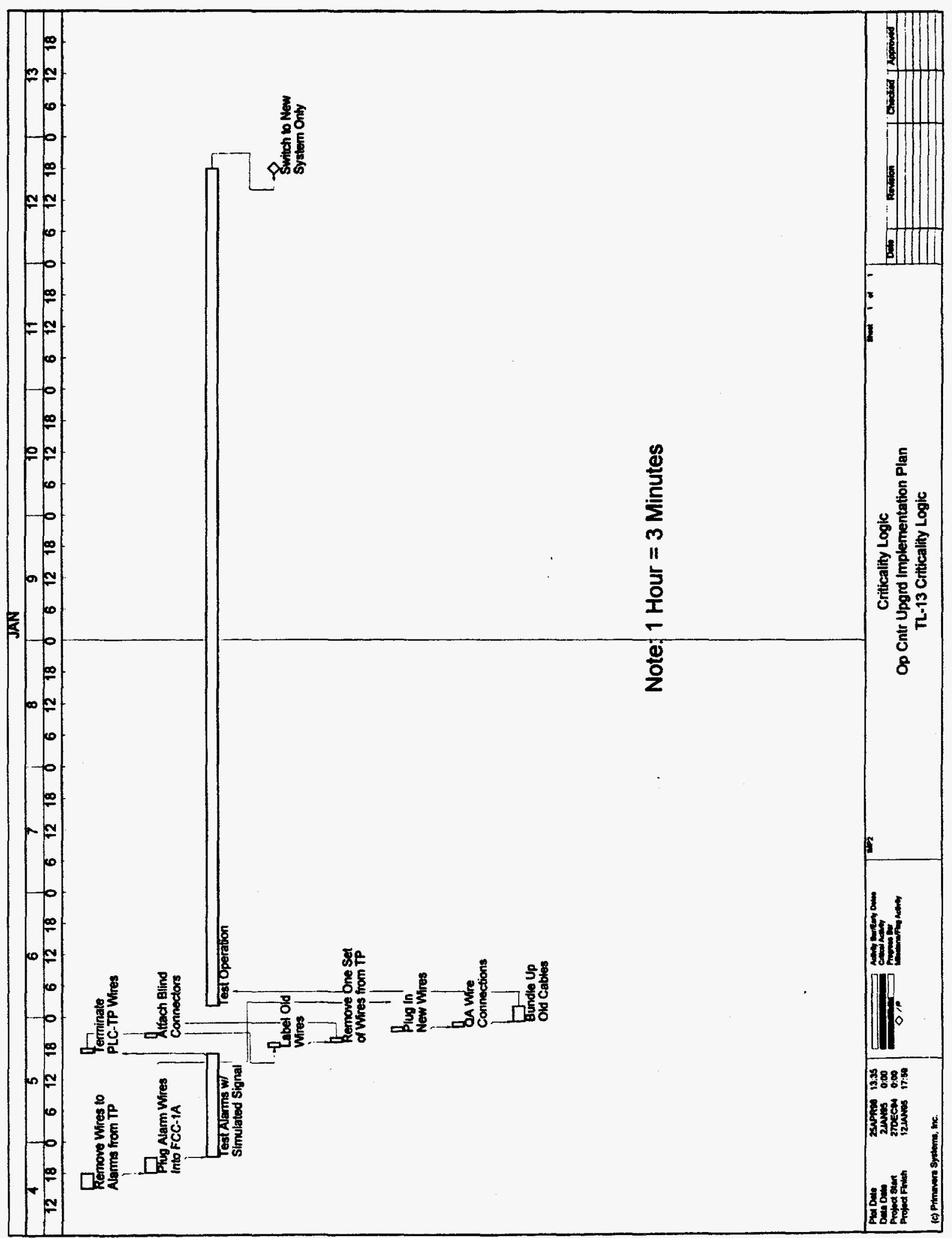




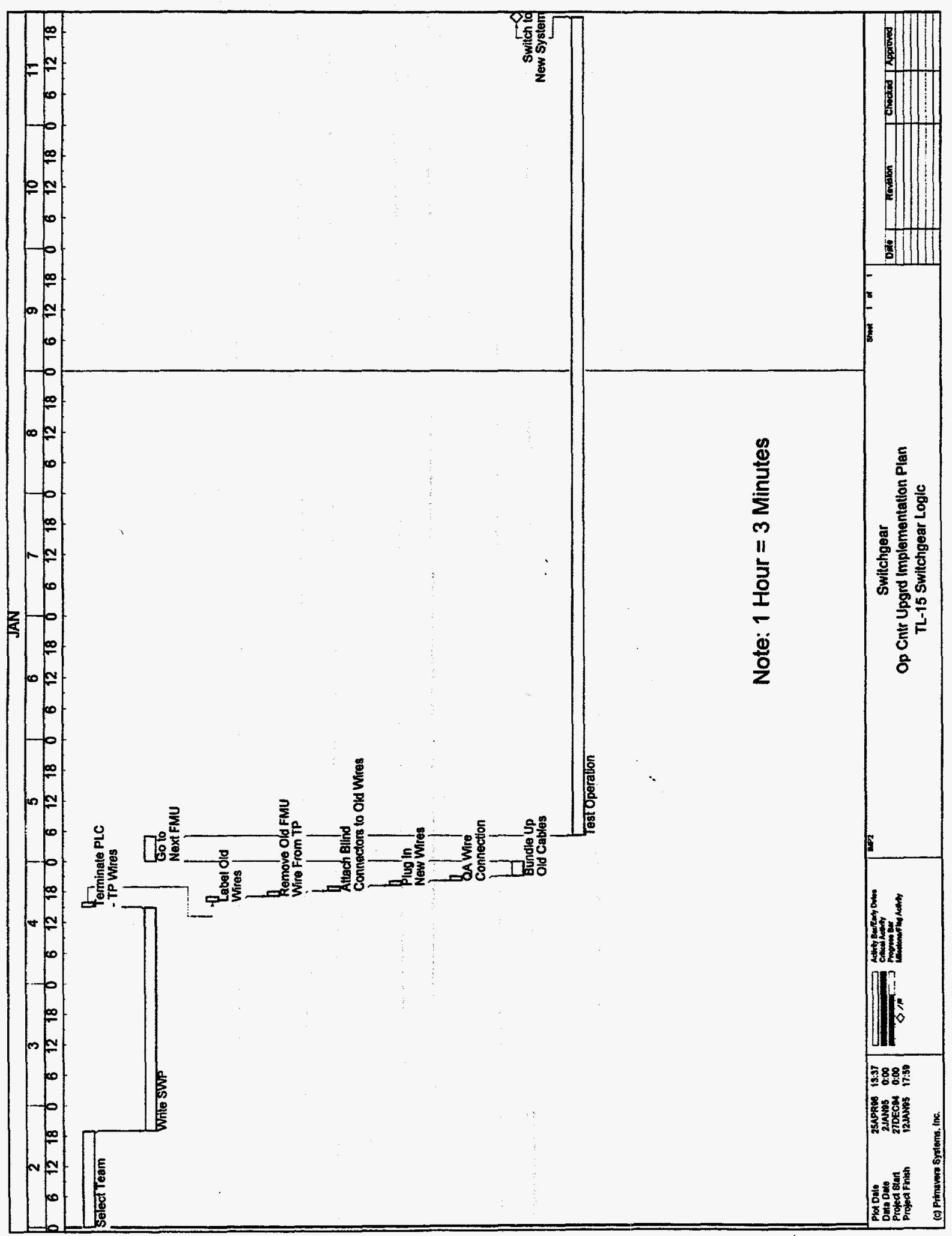




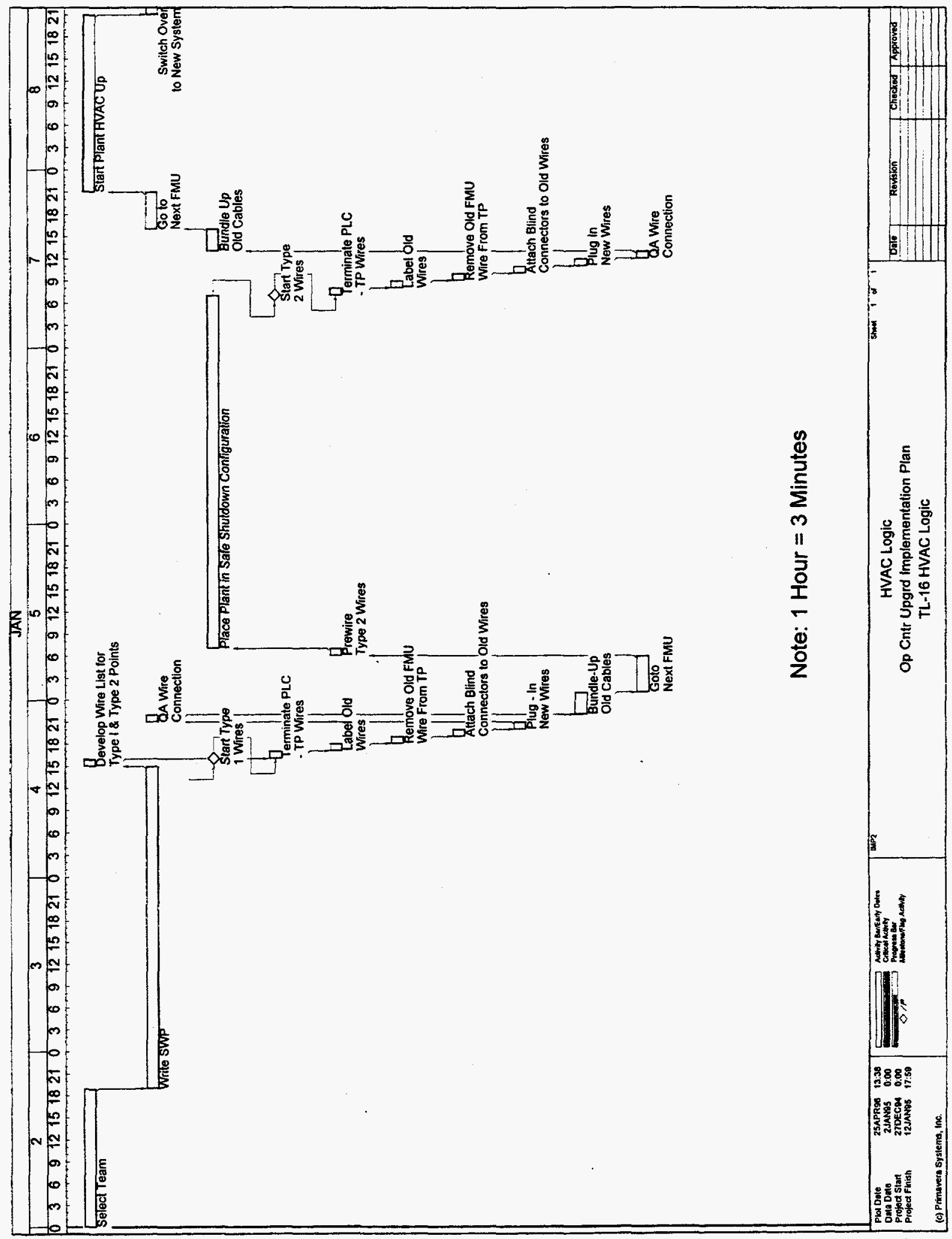




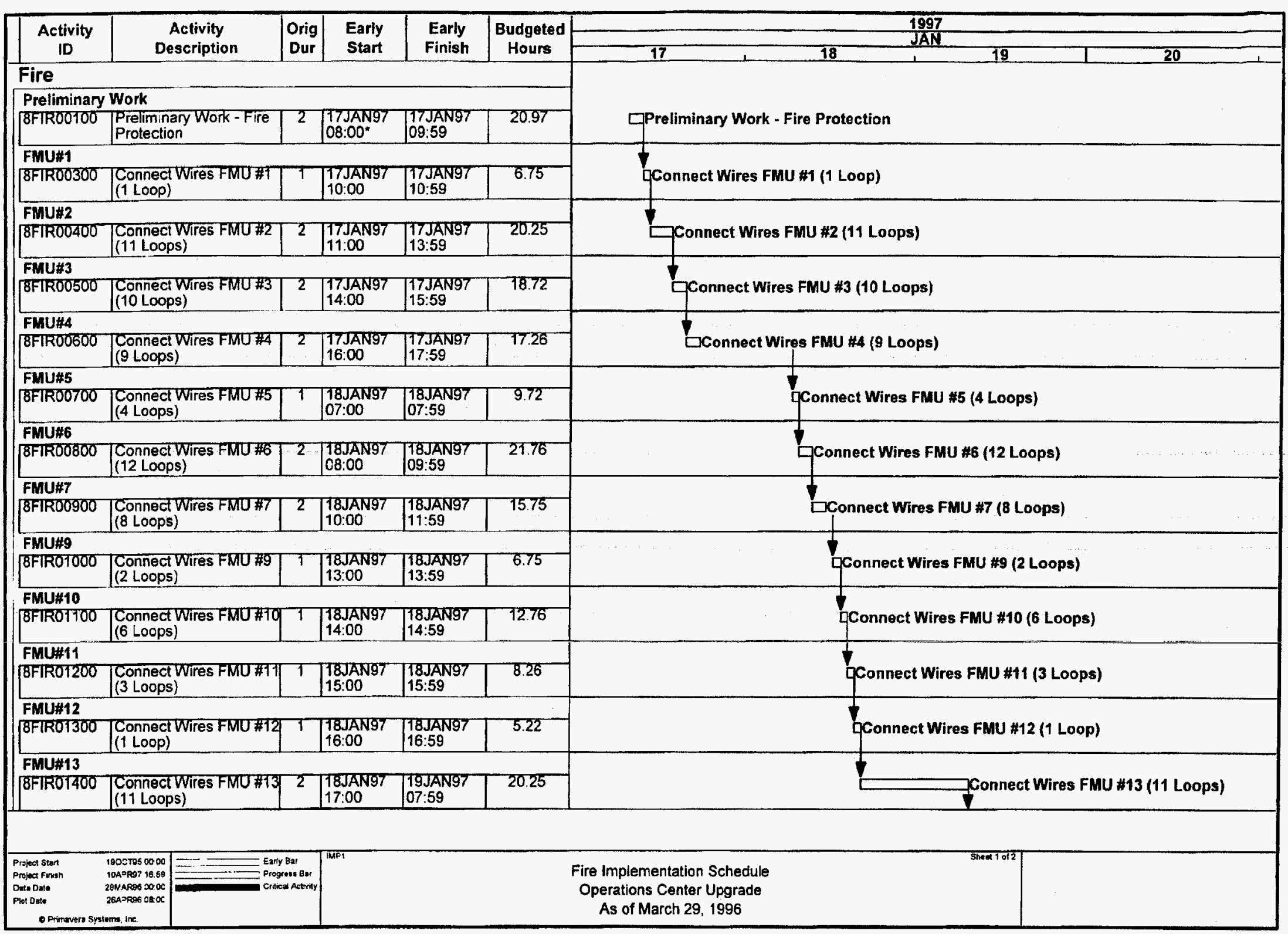

APPENDIX A, CHART D 


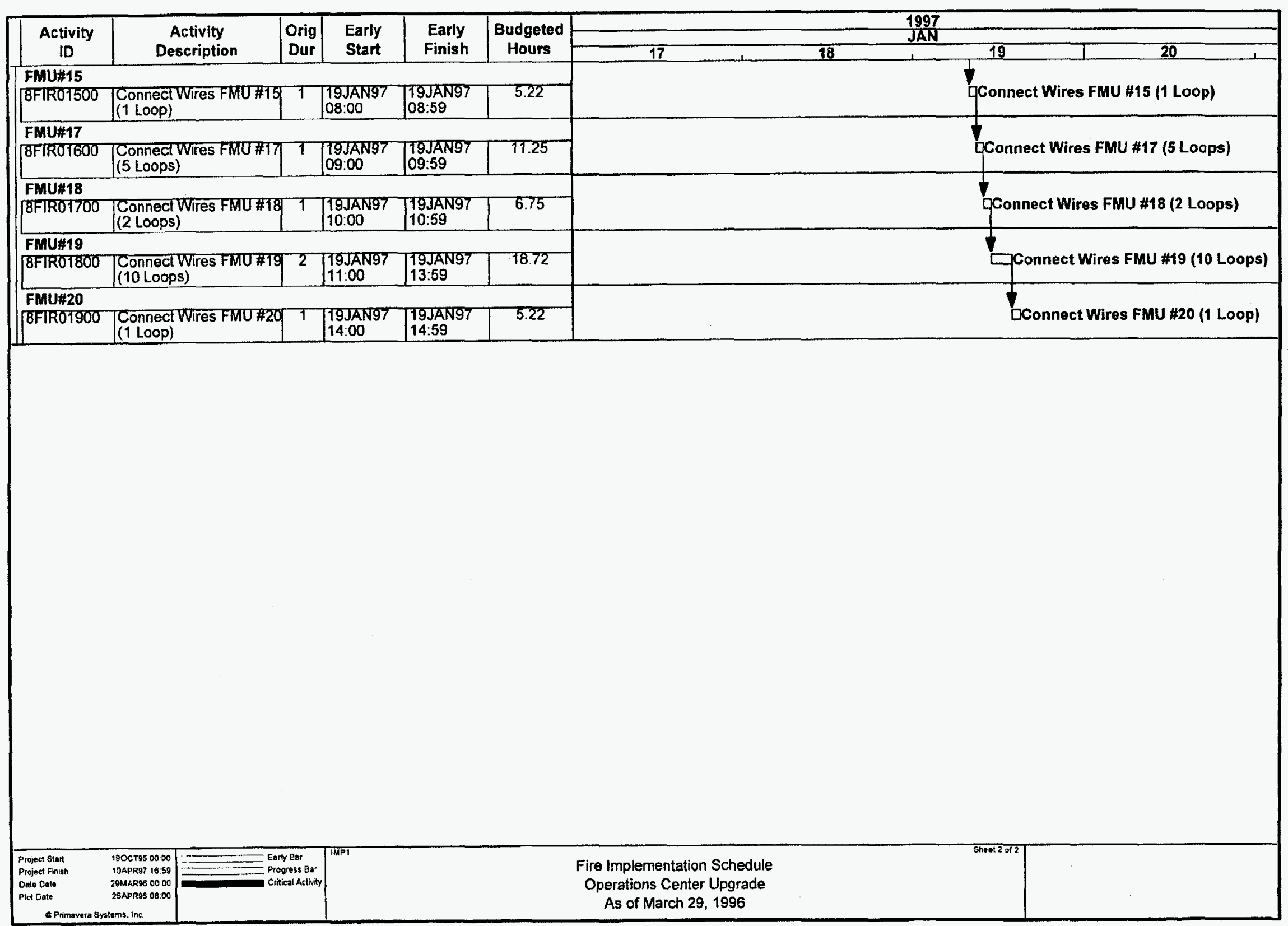




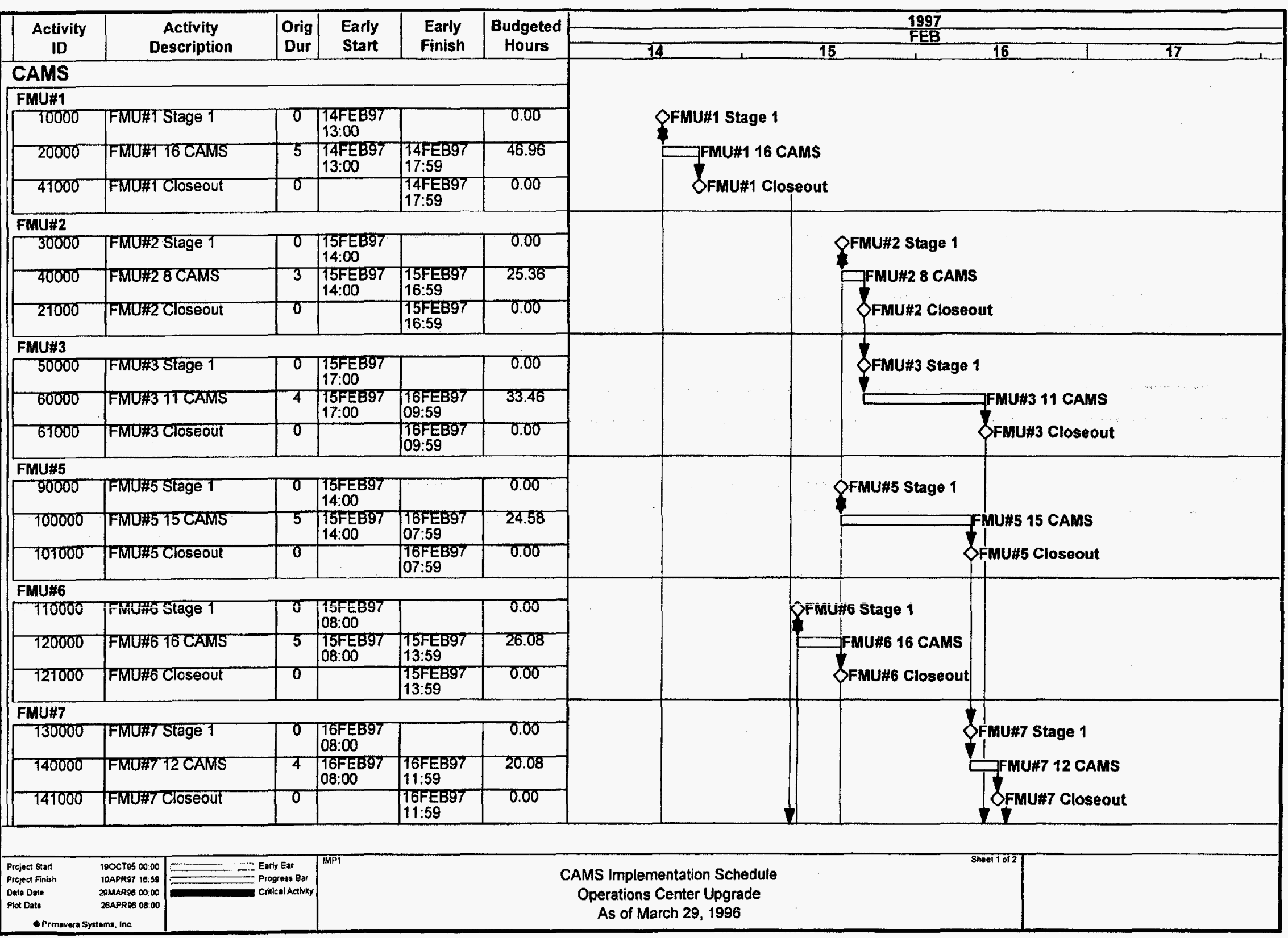




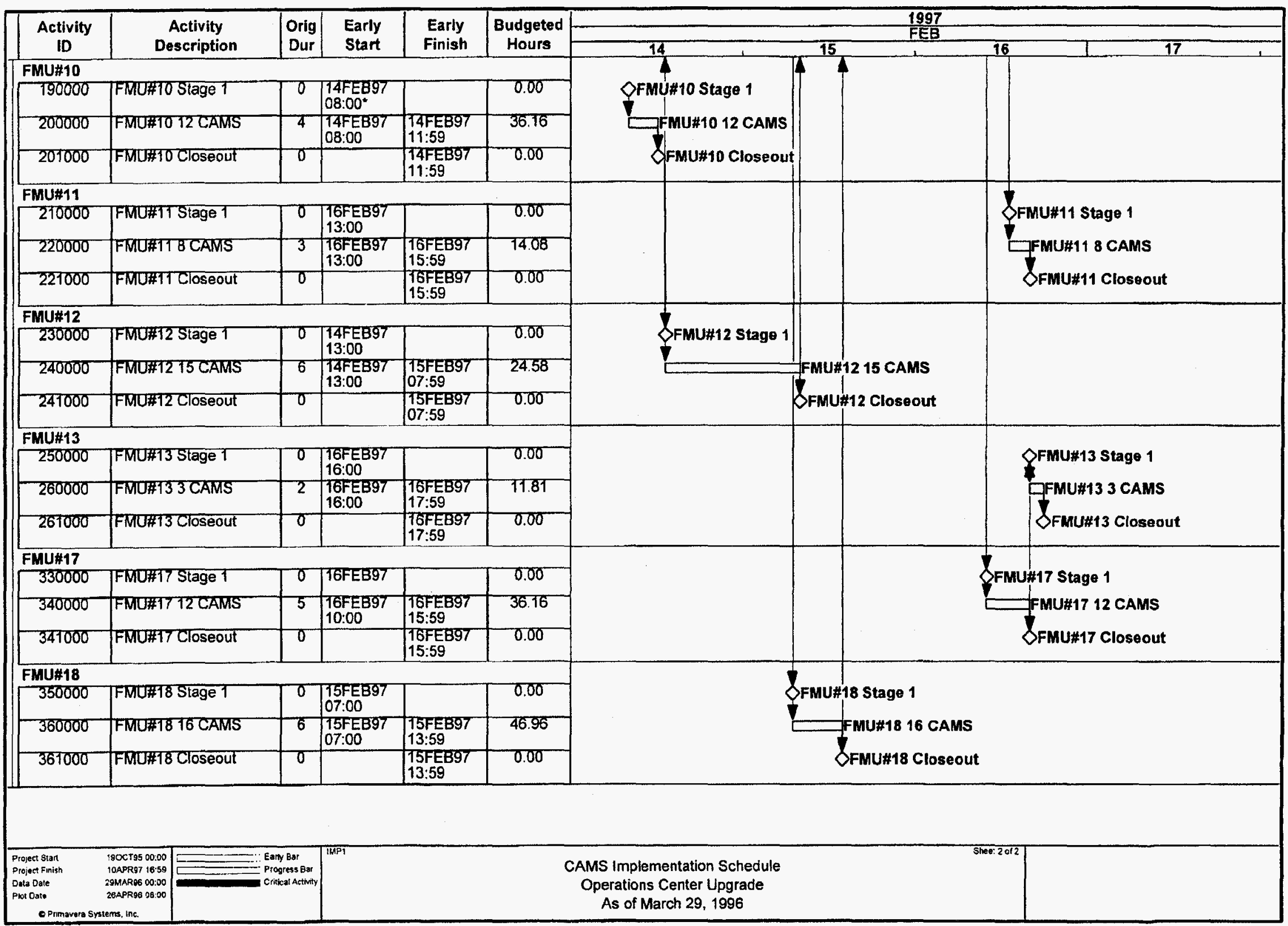




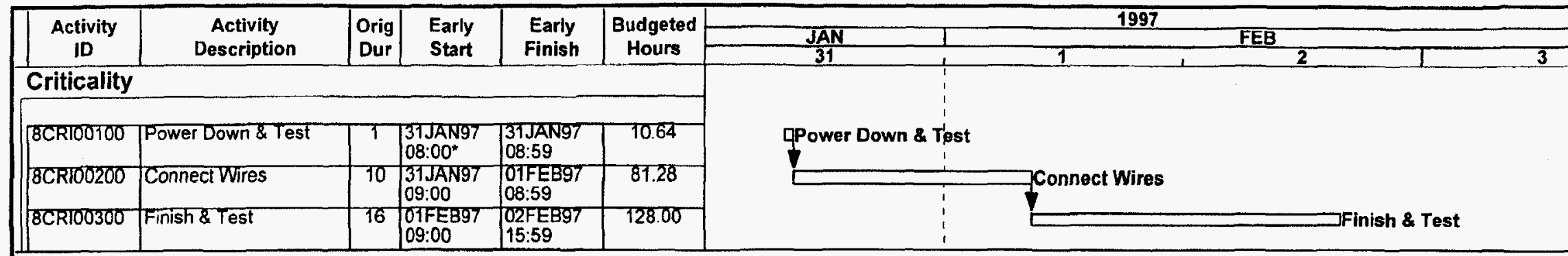

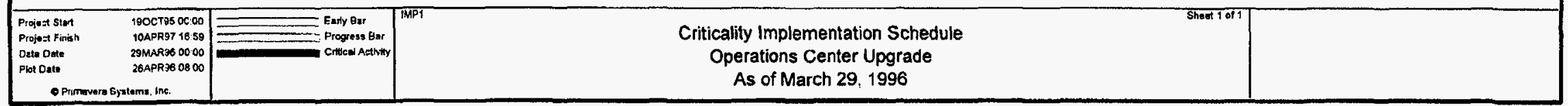




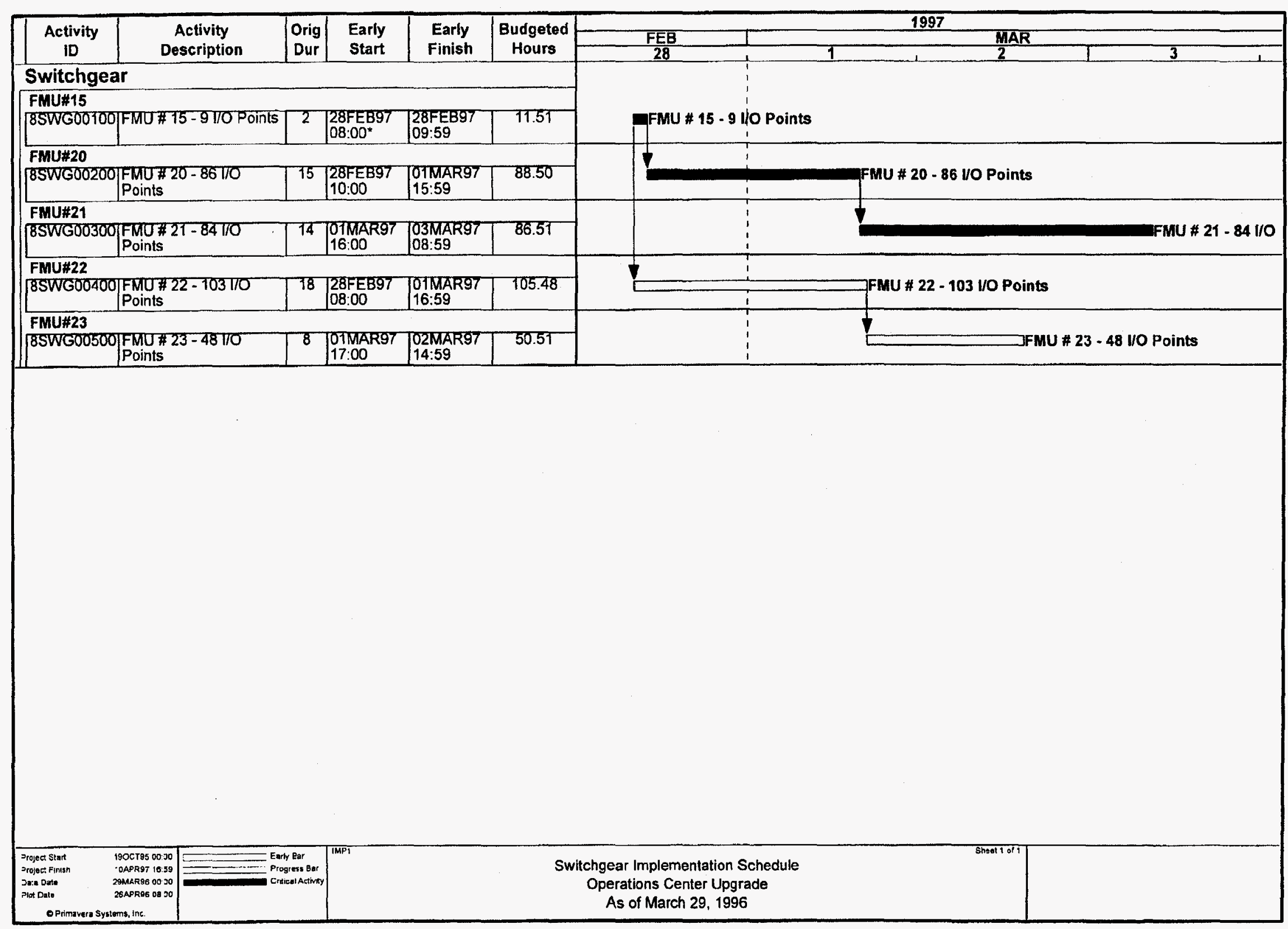




\begin{tabular}{|c|c|c|c|c|c|c|c|c|}
\hline Activity & & Activity & Orig & Early & Early & Budgeted & $\begin{array}{l}\text { MAR } 1997 \\
\end{array}$ & \\
\hline 10 & & scription & Dur & Start & Finish & & $14,15,16|17,18,19,20,21,22,23| 24,25,26,27,28,29,30] 31$ & $1,2,3,4,5,6 \mid 7,8,9,10$ \\
\hline HVAC - $\mathrm{CI}_{\mathrm{I}}$ & rossove & er Type $1 \mathrm{Wi}$ & ires & & & & & \\
\hline FMU\#1 & TरापTसम & 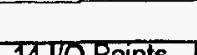 & & & & & & \\
\hline $8 \mathrm{BHVCPOO10}$ & TFMU\#T- & -14110 Points & 3 & $\begin{array}{l}\text { 14MAR97 } \\
07: 00\end{array}$ & $\begin{array}{l}\text { 14MAR97 } \\
\text { 09:59 }\end{array}$ & 19.25 & fFMU \#1 -14 I/O Points & \\
\hline FMU\#2 & & & & & & & & \\
\hline $8 \mathrm{BHVCP0200}$ & TFMU \#2- & $-15 T 10$ Points & 3 & $\begin{array}{l}\text { 14MAR97 } \\
10: 00\end{array}$ & 13:59 & 20.43 & FMU \#2 - 15 ॥O Points & \\
\hline FMU\#3 & & & & & & & & \\
\hline [8HVCPO300 & FMU\#3- & $-141 / 0$ Points & 3 & $\begin{array}{l}\text { 14MAR97 } \\
\text { 14:00 }\end{array}$ & $\begin{array}{l}\text { 14MAAR97 } \\
\text { 16:59 }\end{array}$ & 19.25 & FMU \#3 - 14 UO Points & \\
\hline FMU\#4 & & & & & & & & \\
\hline $8 \mathrm{HVCPO} 400$ & FMU \#4- & $-221 / 0$ Points & 4 & $\begin{array}{l}\text { T4MAR97 } \\
17: 00\end{array}$ & $\begin{array}{l}\text { T5MAR97 } \\
\text { O9:59 }\end{array}$ & 28.56 & FMU \#4 - 22 VO Points & \\
\hline FMU\#5 & & & & & & & & \\
\hline 8HVCPO500 & TFMU\#5. & -5 l/O Points & 1 & $\begin{array}{l}\text { 15MAAR97 } \\
\text { 10:00 }\end{array}$ & $\begin{array}{l}\text { 15MAR97 } \\
\text { 10:59 }\end{array}$ & 8.75 & FMU \#5 - 5 vO Points & \\
\hline FMU\#6 & & करण & & & & & & \\
\hline 8 8HVCPO600 & TFMU \#6. & -12 Iro points & 2 & 11:00 & $\begin{array}{l}\text { 15MAR97 } \\
\text { 13:59 }\end{array}$ & 16.93 & FMU \#6 - 12 l/O Points & \\
\hline FMU\#7 & & & & & & & & \\
\hline 8HVCP0700 & TFMU & - 181/OPoints & 3 & $\begin{array}{l}\text { TMMAR97 } \\
14: 00\end{array}$ & $\begin{array}{l}\text { 15MAR97 } \\
16: 59\end{array}$ & 23.93 & FMU \#7 - 18 I/O Points & \\
\hline FMU\#8 & & & & & & & & \\
\hline 8 8HVCPO8O0 & TFMU \#8- & -31/OPoints & 1 & $\left.\right|_{17: 00} ^{\text {5.MAR97 }}$ & $\begin{array}{l}\text { 15MAR97 } \\
17: 59\end{array}$ & 6.43 & FFU \#8 - 3 I/O Points & \\
\hline FMU\#10 & & & & & & & & \\
\hline 8HVCPO9O0 & TFMU $\# 10$ & $0-171 / 0$ Points & 2 & $\begin{array}{l}\text { T6IMAR97 } \\
07: 00\end{array}$ & $\begin{array}{l}\text { 16MAR97 } \\
\text { O8:59 }\end{array}$ & 16.75 & FMU \#10 - 11 //O Points & \\
\hline FMU\#11 & & & & & & & & \\
\hline BHVCFTOOO & 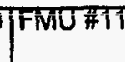 & $1-22$ 10 Points & 4 & TIGMAR9T & $\begin{array}{l}\text { PGNARYT } \\
13: 59\end{array}$ & 28.56 & FMU \#11 - 22 U/O Points & \\
\hline FMU\#12 & & & & & & & & \\
\hline 8HVCP1100 & TFMU \#12 & $2-14$ I/OPoints & 3 & $\begin{array}{l}\text { T6MAR97 } \\
14: 00\end{array}$ & $\begin{array}{l}\text { 16MAR97 } \\
16: 59\end{array}$ & 19.25 & FMU \#12 - 14 I/O Points & \\
\hline FMU\#13 & & & & & & & Gamar & \\
\hline $8 \mathrm{HVCP} 1200$ & FMUU\#13 & 3-101/OPoints & 2 & $\begin{array}{l}\text { T6MAR97 } \\
\text { 17:00 }\end{array}$ & $\begin{array}{l}\text { 77MAR97 } \\
07: 59\end{array}$ & 14.56 & FMU \#13 - 10 VO Points & \\
\hline FMU:17 & & & & & & & & \\
\hline $8 \mathrm{HVCP} 1400$ & JFMU\#T17 & 7-221/OPOints & 4 & $\begin{array}{l}\text { 17MAR97 } \\
\text { 08:00 }\end{array}$ & $\begin{array}{l}\text { T7MAR97 } \\
11: 59\end{array}$ & 28.57 & FFU \#17- 22 I/O Points & \\
\hline 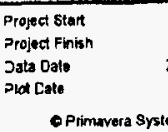 & 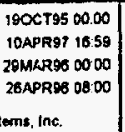 & 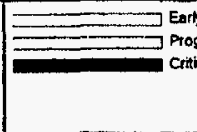 & tin Bart & $T^{\text {IMPT }}$ & & & $\begin{array}{l}\text { HVAC Implementation Schedule } \\
\text { Operations Center Upgrade } \\
\text { As of March 29, } 1996\end{array}$ & \\
\hline
\end{tabular}




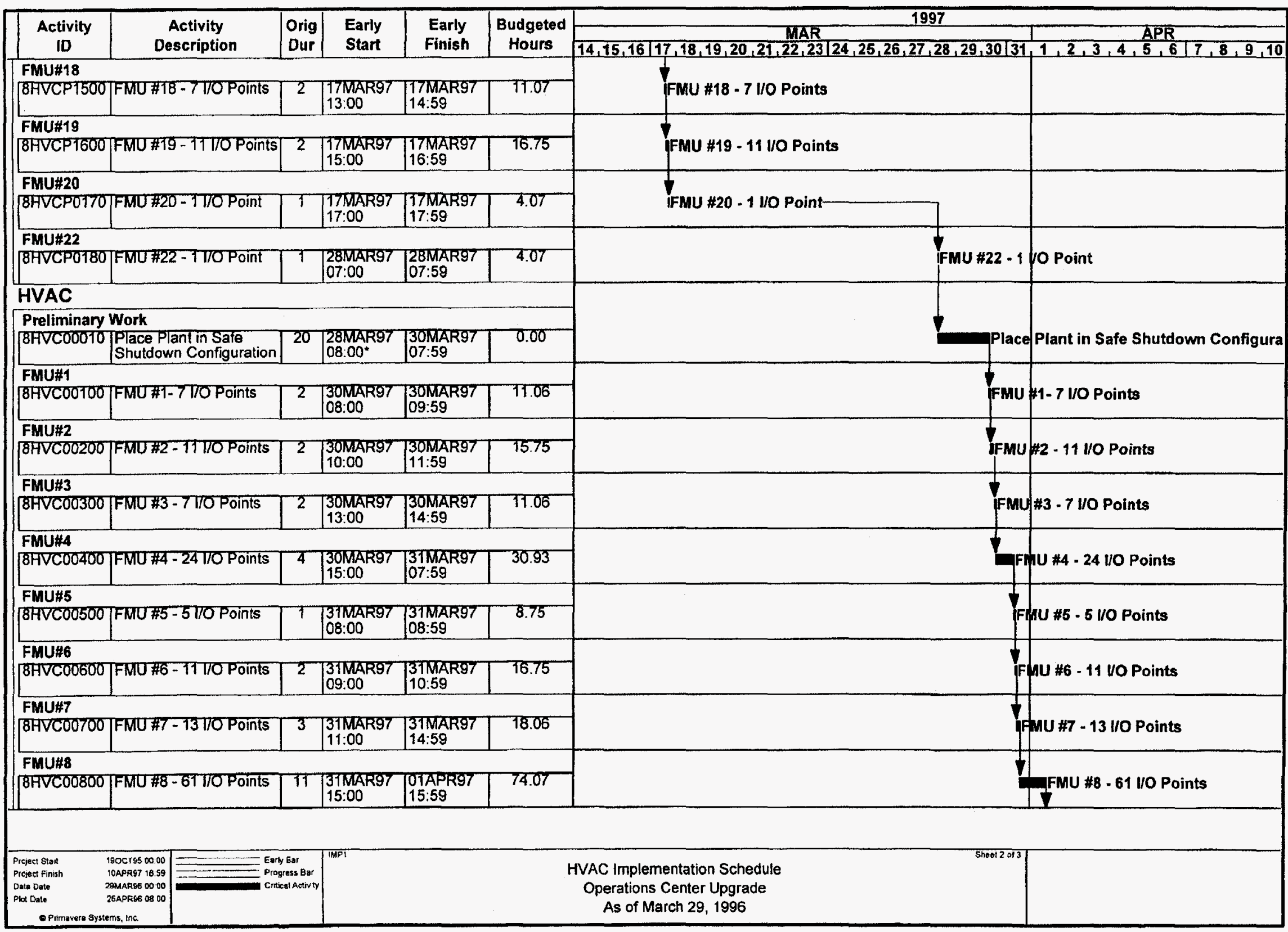




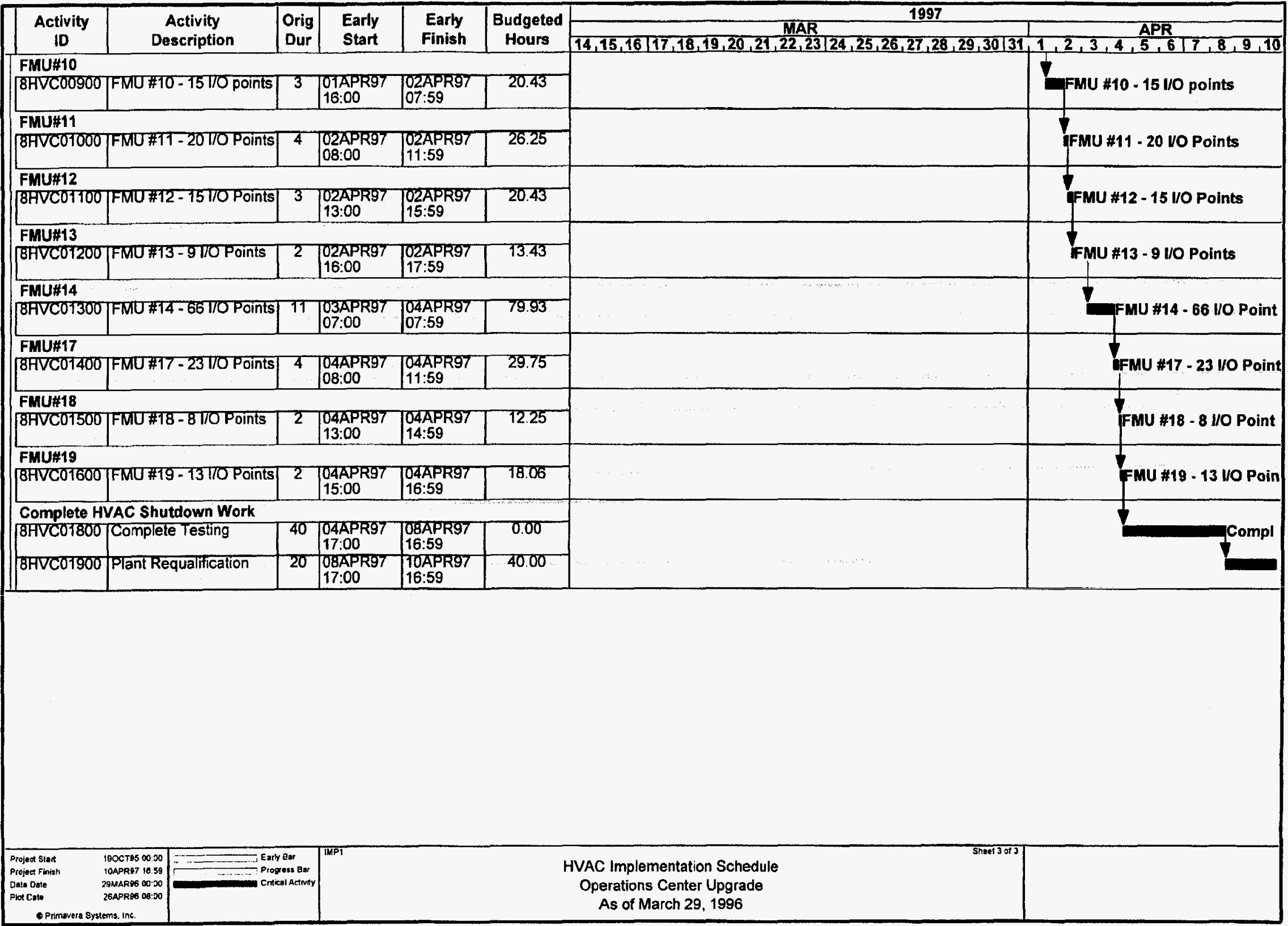


This report has been reproduced directly from the best available copy.

It is available to DOE and DOE contractors from the Office of Scientific and Technical Information, P.O. Box 62 ,

Oak Ridge, TN 37831.

Prices are available from (615) 576-8401.

It is available to the public from the National Technical Information Service, US Department of Commerce, 5285 Port Royal Rd.

Springfield, VA 22616. 